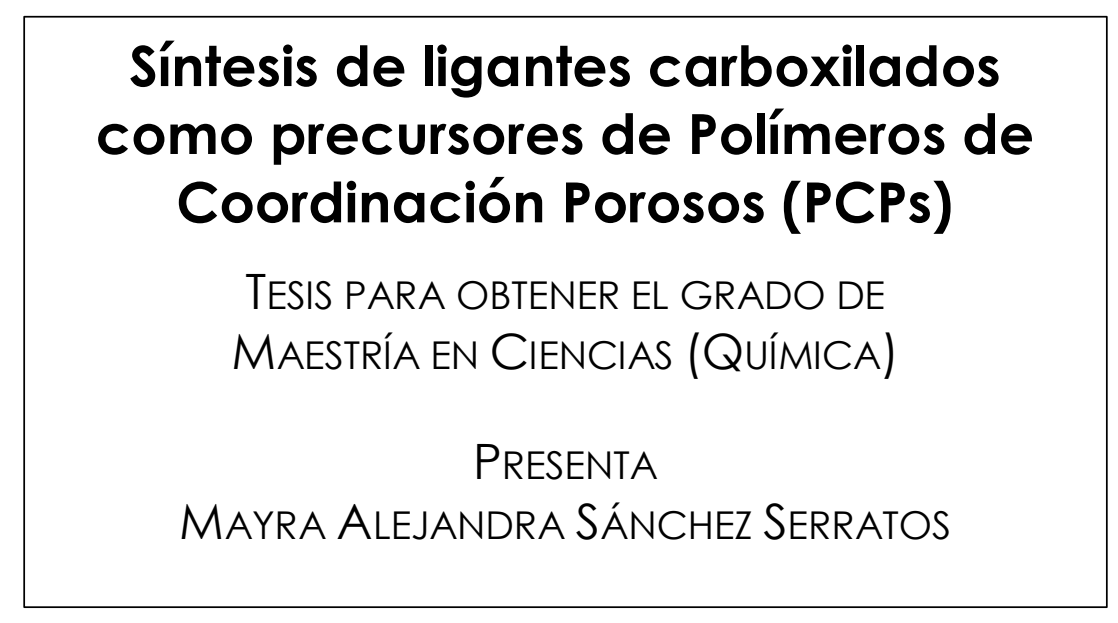

Presidente Dr. Hiram IsaAC Beltrán Conde

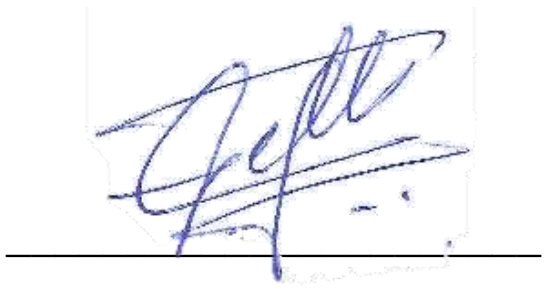

Secretario Dr. Alejandro Islas Jácome

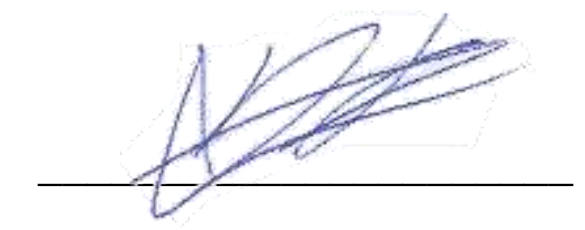

Vocal Dr. Ilich Argel Ibarra Alvarado

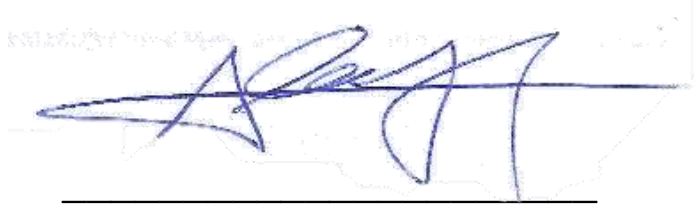




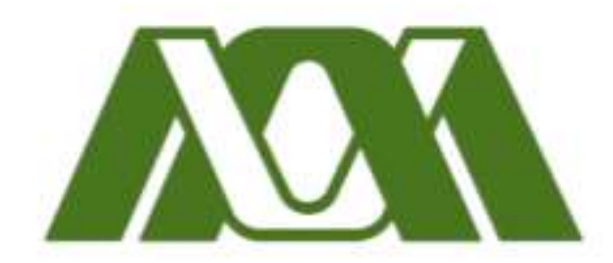

Casa abierta al tiempo

\section{UNIVERSIDAD AUTÓNOMA METROPOLITANA}

UNIDAD IZTAPALAPA

DIVISIÓN DE CIENCIAS BÁSICAS E INGENIERÍA DEPARTAMENTO DE QUIIMICA

\title{
Síntesis de ligantes carboxilados como precursores de Polímeros de Coordinación Porosos (PCPs)
}

\author{
TESIS PARA OBTENER EL GRADO DE \\ MAESTRÍA EN CIENCIAS (QUÍMICA) \\ LIC. EN TECNOLOGÍA \\ MAYRA ALEJANDRA SÁNCHEZ SERRATOS

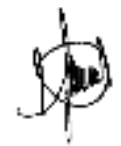 \\ ASESOR \\ DR. EDUARDO GONZÁLEZ ZAMORA
}




\section{Gracias}

A mis padres, Martha Serratos y Guillermo Sánchez.

A mis hermanos, Jhónathan y Esmeralda.

A Andrés.

Por todo su amor y su apoyo. A ustedes dedico este trabajo. 
El presente trabajo de tesis se realizó en el laboratorio R-103 del Departamento de Química de la Universidad Autónoma Metropolitana, Unidad Iztapalapa.

Para la realización de este proyecto se contó con el apoyo económico del Consejo Nacional de Ciencia y Tecnología (CONACYT CVU: 398285, No. Becario 615217). 


\section{ÍNDICE}

AGRADECIMIENTOS

V

LISTA DE ABREVIATURAS VI

$\begin{array}{lll}\text { RESUMEN } & \text { VII }\end{array}$

PLANTEAMIENTO DEL PROBLEMA VIII

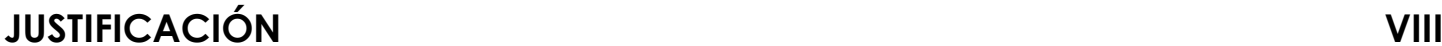

1. Introducción 1

1.1. PCPs 2

1.1.1. Síntesis 2

1.2. Ligantes orgánicos 4

1.3. Síntesis de los PCPs

1.3.1. Síntesis solvotermal/hidrotermal 6

1.3.2. Síntesis asistida por microondas.

1.3.3. Síntesis electroquímica

1.3.4. Síntesis sonoquímica

1.3.5. Síntesis mecanoquímica.

1.4. Aplicaciones de PCPs 7

1.4.1. Catálisis 8

1.4.2. Biomedicina 8

1.4.3. Separación y almacenamiento de gases 9

2. Antecedentes 10

2.1. Reacciones de acoplamiento 10

2.1.1. Perspectiva histórica 10

2.1.2. Ciclo catalítico 11

2.2. Acoplamiento Suzuki-Miyaura 11

3. OBJETIVOS 12

4. Resultados y discusión $\quad 14$

4.1. Moléculas previas 14

4.2. Ligante L1 16

4.3. Ligante L2 17 
4.4. Ligante L3

4.5. Ligante $L 4$

5. Conclusiones y Perspectivas 23

6. Parte experimental $\quad 24$

i. Puntos de fusión $\quad 24$

ii. Espectros de Infarrojo $\quad 24$

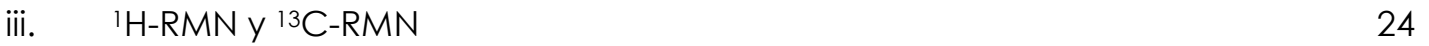

iv. Espectroscopia de masas 24

6.1. Dietil 4,4'-(antracen-9,10-diil) dibenzoato (Compuesto C). 25

6.2. Ácido 4,4'-(antraceno-9,10-diil)dibenzoico (P1) 27

6.3. Ácido 4,4'-([9,9'-biantraceno]-10,10'-diil) dibenzoico (L1) 29

6.4. Ácido 5-boronoisoftálico (Compuesto 4) 33

6.5. Ácido (3,5-bis(etoxicarbonil)fenil) borónico (Compuesto 7) 37

6.6. 9,10-bis ((trimetil silil)etinil)antraceno (Compuesto 10) 40

6.7. Ácido (E)-5,5'-(diazene-1,2-diil)di-isoftálico (Compuesto 14) 42

6.8. Ácido (2E,2'E)-4,4'-1,4-fenilenobis(azadiil) bis(4-oxobut-2-enoico) (L5) 45

$\begin{array}{ll}\text { 7. Referencias } & 48\end{array}$ 


\section{AGRADECIMIENTOS}

Al Dr. Eduardo González Zamora, por permitirme trabajar en su grupo de investigación, por su asesoría durante mis estudios de Maestría, por todo su apoyo y sus consejos.

A los miembros del jurado: Dr. llich Argel Ibarra Alvarado, Dr. Alejandro Islas Jácome y al Dr. Hiram Isaac Beltrán Conde.

Al Laboratorio de Resonancia Magnética Nuclear (UAM-I), al M. en C. Atilano Gutiérrez Carrillo y al M. en C. Marco Antonio Vera Ramírez por los espectros de RMN.

A la B. Mónica A. Rincón por su apoyo para la obtención de los espectros de Masas.

A la Dra. Liliana Iraís Vera Robles, responsable del laboratorio de docencia, y a la técnico Citali Arroyo por su apoyo para la obtención de los espectros de FTIR.

A mis compañeros y amigos del grupo de investigación Natalia, Daniel, Ivette, Yizrell, Mayra, Perla, Edrey, Julio, Oscar, Diana y Gersael, por su apoyo y todos los buenos momentos compartidos a lo largo de la duración de este trabajo de investigación. 


\section{LISTA DE ABREVIATURAS}

\begin{tabular}{|c|c|}
\hline Hex & Hexano \\
\hline AcOEt & Acetato de etilo \\
\hline TLC & Cromatografía de capa fina \\
\hline DMF & Dimetilformamida \\
\hline DMSO & Dimetilsulfóxido \\
\hline $\mathrm{Et}_{3} \mathrm{~N}$ & Trietilamina \\
\hline E†OH & Etanol \\
\hline $\mathrm{MeOH}$ & Metanol \\
\hline MOFs & Metal Organic Frameworks (Redes Metal Orgánicas) \\
\hline MPS & Modificación Post-Sintética \\
\hline NNDAA & N, N-Dimetilacetamida \\
\hline PCPs & Polímeros de Coordinación Porosos \\
\hline PhMe & Tolveno \\
\hline TA & Temperatura ambiente \\
\hline THF & Tetrahidrofurano \\
\hline SBUS & Unidades de construcción secundarias \\
\hline
\end{tabular}




\section{RESUMEN}

En este trabajo de tesis se presenta la síntesis de ligantes bi- y tetra-carboxilados que pueden ser utilizados en la síntesis de nuevos Polímeros de Coordinación Porosos tipo MOF.

Inicialmente se describen las características de los PCPs. De igual forma, se exponen los principales métodos de síntesis utilizados y las aplicaciones más reportadas. Posteriormente se presentan las reacciones más utilizadas para la síntesis de ligantes carboxilados.

Finalmente se describe el proceso de síntesis, caracterización y los resultados obtenidos del presente trabajo. 


\section{PlanteAMIENTO Del PROBLEMA}

Los Polímeros de Coordinación Porosos (PCPs), mejor conocidos como MOFs (Metal Organic Frameworks) son una clase de materiales híbridos porosos que han tenido un gran auge en las últimas décadas. Su porosidad, su alta estabilidad térmica y la gran variedad de estructuras posibles hacen de estos materiales candidatos prometedores para diversas aplicaciones, entre las que destacan: captura y almacenamiento de gases, catálisis, transporte y liberación de fármacos, y como sensores químicos. Sin embargo, el stock de ligantes comercialmente disponibles con proveedores de reactivos químicos finos es limitado. De hecho, ya hay reportes de síntesis de MOFs utilizando la mayoría de los ligantes comercialmente disponibles.

\section{JUSTIFICACIÓN}

Si bien el componente inorgánico de los PCPs está limitado a los metales existentes, no es el caso de su componente orgánico; la imaginación define el límite de la lista de posibles ligantes.

Los ligantes destinados a la síntesis de PCPs deben ser dentados, es decir, tener grupos funcionales terminales que puedan coordinarse con cationes metálicos; de modo que pueda existir una interacción que dé lugar a una nueva estructura. En respuesta al creciente número de investigaciones relacionadas con estos materiales y sus múltiples aplicaciones, ya existen ligantes a la venta; sobre todo aquellos destinados a la síntesis de los PCPs pioneros o más representativos, por ejemplo, el MOF-1 y el HKUST. Sin embargo, hay un catálogo finito para crear estructuras ya conocidas o reportadas. Con esto en mente, el presente trabajo busca explorar la síntesis de ligantes que puedan dar lugar a nuevos PCPs. 


\section{INTRODUCCIÓN}

Los Polímeros de Coordinación Porosos (PCPs) son una clase emergente de materiales que se encuentran en la frontera de la química orgánica y la inorgánica. Al ser una clase nueva de materiales, no existe aún un término general para ellos. Han sido nombrados como sólidos porosos híbridos [1, 2], polímeros de coordinación [3], redes de coordinación metal-orgánicas o MOCNs por sus siglas en inglés (metalorganic coordination networks) [4], redes metal-orgánicas o MOFs por sus siglas en inglés (metal-organic frameworks) [5].

La IUPAC ha hecho recientemente algunas recomendaciones en cuanto a la terminología apropiada para estos materiales [6], concluyendo que tanto polímeros de coordinación porosos (PCPs) y MOFs son términos aceptados. En el presente trabajo nos referimos a estos materiales como Polímeros de Coordinación Porosos (PCPs).

De igual modo, son aceptadas siglas a manera de nombre para identificar a un PCP o una familia de PCPs en particular [6]. Este forma de nombrarlos, adoptado de los nombres de las zeolitas [2], hace referencia al origen geográfico donde fueron sintetizados. Podemos mencionar algunos ejemplos como: la serie MIL-n (Matériaux de l'Institut Lavoiser) sintetizada en el Instituto Lavoisier por el grupo de G. Férey [7], la serie NOTT-n creada en la Universidad de Nottingham por el grupo de M. Schröder [8] y el PCP HKUST-1, sintetizado en la Universidad de Ciencia y Tecnología de Hong-Kong (Hong Kong University of Science and Technology) [9].

La creación de uno de los primeros polímeros de coordinación se remonta al pigmento azul de Prusia, aunque su naturaleza fue descubierta tiempo después [10]. Se tiene registro de un artículo publicado por el Journal of the College of Science, de la Universidad de Tokio en 1916 [1], en el que se menciona por primera vez el término polímero de coordinación. El primer polímero de coordinación con una fórmula química fue sintetizado por Hofmann y Küspert en 1897, la cual es $\mathrm{Ni}(\mathrm{CN})_{2}\left(\mathrm{NH}_{3}\right) \cdot \mathrm{C}_{6} \mathrm{H}_{6} .{ }^{[12]}$. De igual modo, su estructura no fue conocida hasta 1954.

A pesar de la temprana aparición de este tipo de polímeros, hubo un largo periodo sin que fueran estudiados. No fue sino hasta la publicación de dos artículos en 1989 y 1990 respectivamente [13, 14] cuando comenzó un verdadero interés por ellos. El trabajo de Hoskins y Robson estableció una nueva estrategia para diseñar nuevos sólidos porosos con grandes cavidades formados por subelementos orgánicos e inorgánicos, siendo su trabajo un parteaguas en la síntesis de estos materiales. En estos dos primeros artículos, Hoskins y Robson se refieren a estos materiales como redes poliméricas infinitas. Pocos años después aparecerían, de forma casi simultánea y en grupos de investigación diferentes, dos artículos más en los que se 
les presenta formalmente y por primera vez como redes metal-orgánicas (MOFs) [15] y polímeros de coordinación (PC) ${ }^{[16]}$.

\subsection{PCPs}

\subsubsection{Síntesis}

Similar a las zeolitas, los Polímeros de Coordinación Porosos consisten en redes infinitas de unidades estructurales interconectadas, pero a diferencia de éstas y su carácter inorgánico, las unidades que forman a los PCPs son orgánicas e inorgánicas. Los PCPs están formados por dos componentes esenciales: iones metálicos y ligantes orgánicos, éstos se unen en un proceso de auto-ensamblaje mediante enlaces de coordinación formando un arreglo cristalino [10, 12]. En el proceso de auto-ensamblaje (Figura 1-1), los enlaces de coordinación y su carácter reversible juegan un papel importante. Si durante la síntesis hubiera un error en el ensamblaje, éste puede ser fácilmente corregido durante el proceso, obteniendo así una estructura periódica [10]. En estas estructuras también existen otras interacciones que ayudan a su formación, como son puentes de hidrógeno, interacciones $\pi-\pi$ y fuerzas de van der Waals $[4,17]$. Estas interacciones le proporcionan estabilidad a la estructura y la capacidad de mantener la porosidad [10].

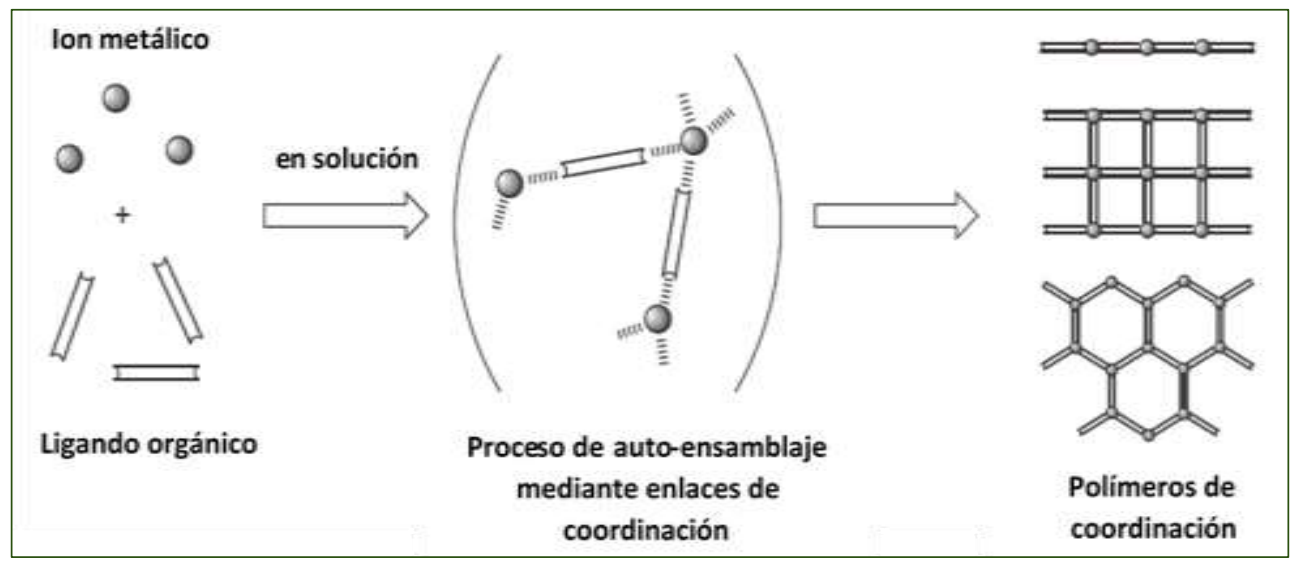

Figura 1-1. Formación de polímeros de coordinación. [17]

Los iones metálicos utilizados suelen ser metales de transición o lantánidos. El número de coordinación del ion metálico usado (normalmente de 2 a 7 para los metales de transición y de 7 a 10 para los lantánidos) [17], dará al PCP una geometría particular. Por ejemplo, para los metales de transición podemos encontrar: lineal, trigonal plana, en forma de T, tetraédrica, cuadrada plana, piramidal cuadrada, octaédrica, prismática, bipiramidal trigonal y bipiramidal pentagonal [17, 18]. Estas 
geometrías pueden predecirse o controlarse según el método de síntesis utilizado. En el caso de los lantánidos, es difícil controlar su geometría debido a su número de coordinación, pero al mismo tiempo esto los vuelve atractivos para la creación de nuevos PCPs con topologías inusuales [17].

En ocasiones se utilizan aglomerados metálicos (clusters) como conectores, estos pueden tener dos o más centros metálicos y ligantes multidentados (carboxilatos), a estas unidades se les ha nombrado unidades secundarias de construcción SBUs (secondary building units) [19] y ayudan a describir la geometría de estas unidades (este término ha sido adoptado del análisis estructural de las zeolitas ${ }^{[5]}$ ). Las SBUs son lo suficientemente rígidos, ya que los carboxilatos mantienen "atrapados" a los iones metálicos en sus posiciones. Entonces, las SBUs sirven de vértices en la estructura en lugar de un solo ion metálico, esto da la posibilidad de producir PCPs más extensos y con una alta estabilidad estructural [20]. Cabe señalar que una SBU es una unidad conceptual, es decir, que no es empleada en la síntesis como un bloque más de construcción. Sin embargo, SBUs específicas pueden ser creadas in situ con las condiciones de reacción adecuadas ${ }^{[19]}$.

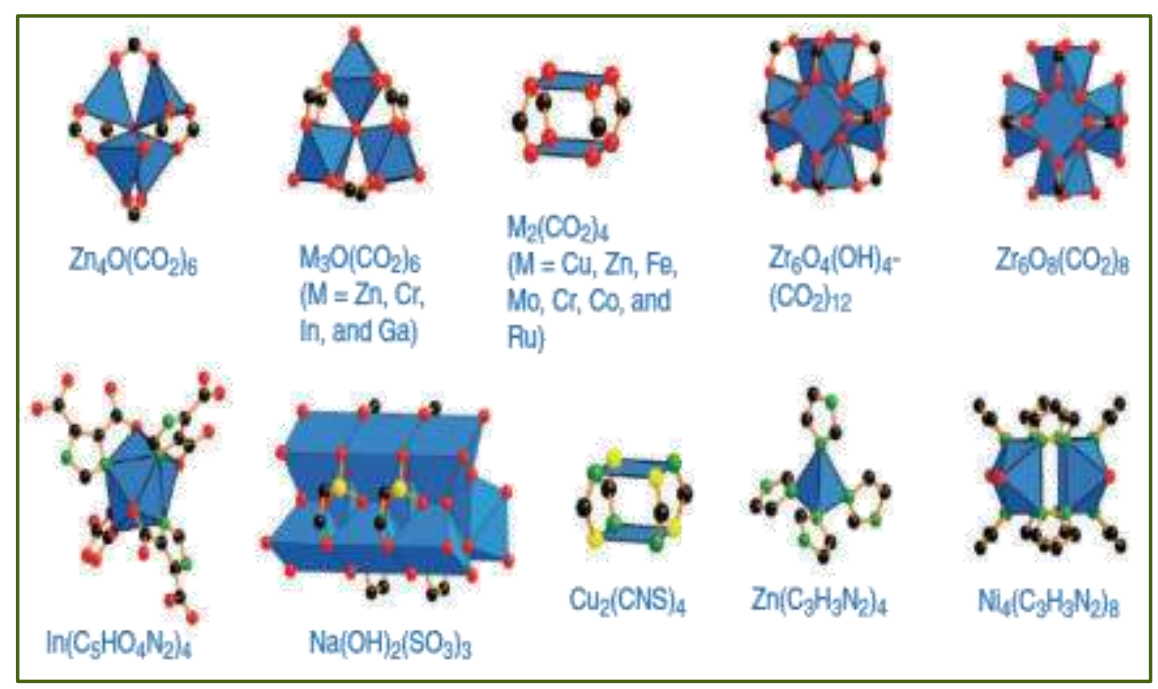

Figura 1-2. Unidades de construcción secundarias (SBUs). Código de color: negro - C; rojo - O; verde - N; amarillo - S; poliedros azules - iones metálicos. No se muestran los átomos de hidrógeno para mayor claridad. [21]

Este enfoque basado en el concepto de SBU ha sido útil para la topología de las estructuras de los PCPs y ha permitido la síntesis y el uso de diversos ligantes orgánicos y SBUs con diversas geometrías [5]; además ha ayudado al desarrollo de PCPs con porosidad permanente [21]. En la Figura 1-2 se muestran algunas SBUs que han sido reportadas [21]. 


\subsection{Ligantes orgánicos}

Los ligantes orgánicos funcionan como "puentes" entre los centros metálicos. Para que la red pueda extenderse infinitamente, éstos deben ser multidentados con al menos dos átomos donadores, los cuales suelen ser N, O ó S [18].

Los ligantes pueden ser neutros, catiónicos o aniónicos, siendo estos últimos los más utilizados, en la forma de carboxilatos. Éstos a su vez, han sido utilizados en forma bi-, tri-, tetra-, hexa-y hasta octa-dentada [22]. En la Figura 1-3 se muestran los ligantes más representativos, esto muestra la gran variedad que existe en cuanto al diseño y síntesis de PCPs.

Dentro de los ligantes neutrales frecuentemente utilizados están la pirazina y la 4,4'bipiridina ${ }^{[17]}$. De los ligantes aniónicos más recurridos podemos mencionar los di-, tri, tretra- y hexa-carboxilados [17]. Existen muy pocos ejemplos de polímeros de coordinación con ligantes catiónicos, debido a su poca afinidad con los iones metálicos [19].

Debido a la carga catiónica de los iones metálicos, al usar ligantes neutrales es necesario agregar aniones para neutralizar la carga. Los aniones inorgánicos más utilizados son el $\mathrm{ClO}_{4}^{-}, \mathrm{BF}_{4}^{-}, \mathrm{NO}_{3}{ }^{-}, \mathrm{NCS}^{-}, \mathrm{PF}_{6}{ }^{-}, \mathrm{NO}_{2}{ }^{-}, \mathrm{SiF}_{6} 2^{-}, \mathrm{CN}^{-}, \mathrm{CF}_{3} \mathrm{SO}_{3}{ }^{-}, \mathrm{SO}_{4}{ }^{--}, \mathrm{N}_{3}{ }^{-}$y los haluros. Estos son introducidos junto con el metal en forma de sales [19]. Además de neutralizar, estos aniones tienen otras funciones como ser huéspedes en los espacios vacíos o formar parte del ligante. Además, pueden dar lugar a puentes de hidrógeno y funcionar así como reguladores de la estructura del PCP [17-19].

Los ligantes orgánicos tienen un rol importante en la funcionalidad de los PCPs, ya que afectan directamente a su estructura, reactividad química, capacidad de participar en interacciones no covalentes específicas (o no específicas) o en sus propiedades físicas ${ }^{[23]}$.

La reactividad de los ligantes también ha sido explorada mediante la Modificación Post-Sintética, es decir, introducir o remover algún grupo funcional del ligante una vez formado el PCP[24]. Por ejemplo, Cohen y colaboradores utilizaron los grupos amino expuestos de un PCP con ligantes carboxilados para crear un PCP más hidrofóbico mediante la acilación con largas cadenas de cloruro de acilo[25].

Por otro lado, se sabe que las propiedades ópticas de algunas moléculas orgánicas pueden verse afectadas al pasar del estado sólido a disolución. Los PCPs pueden servir como plataformas que inmovilizan a los ligantes afectando sus propiedades de emisión. Recientemente, el grupo de Dincă demostró que el tetrafeniletileno (TPE), el cual no fluoresce en disolución, activa su emisión al estar incorporado en

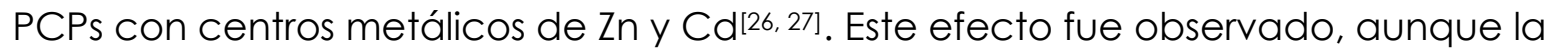
libre rotación del ligante no fue del todo suprimida. 


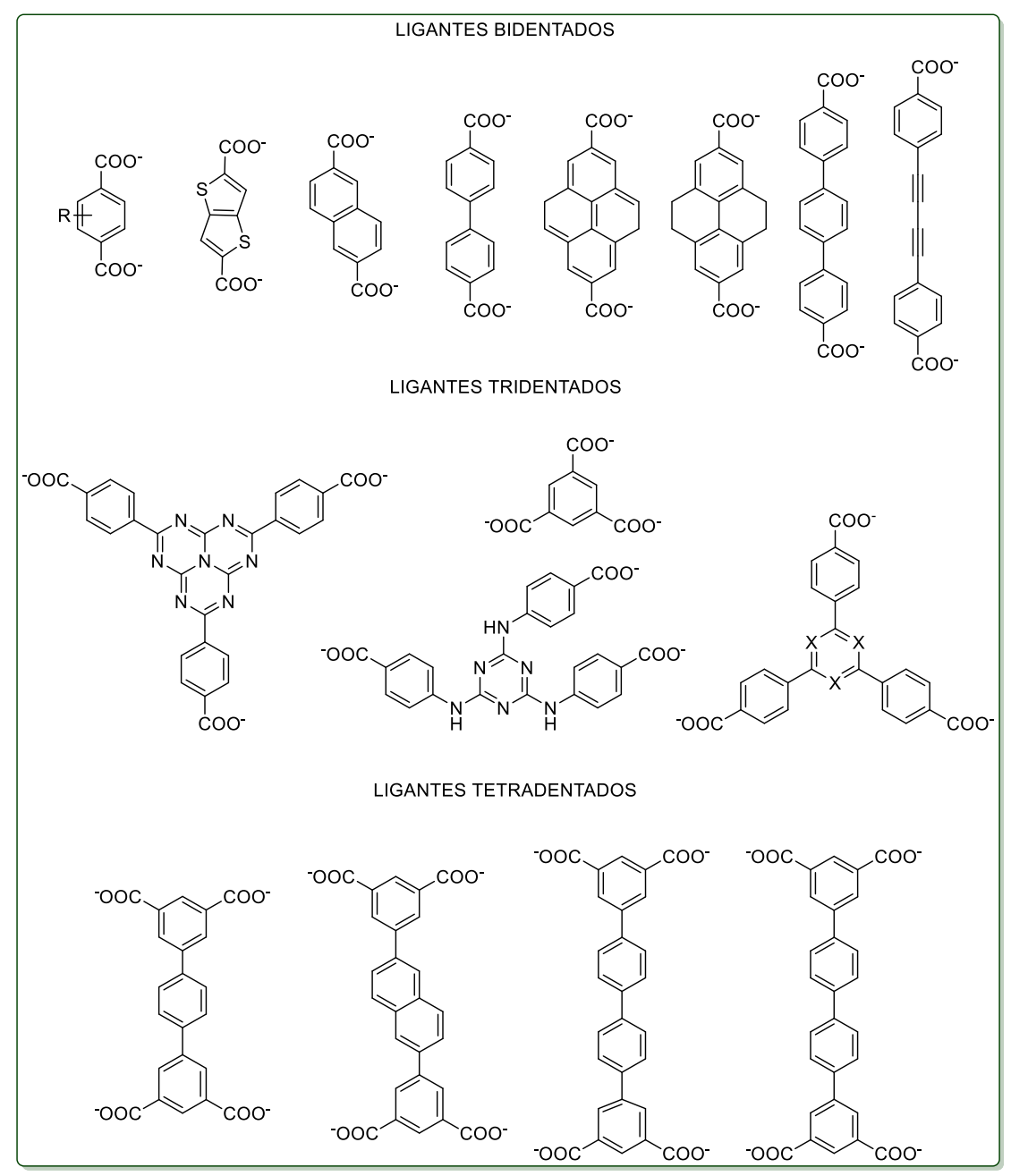

Figura 1-3. Ligantes carboxilados más representativos [22].

\subsection{Síntesis de los PCPs}

Los PCPs son generalmente sintetizados en fase líquida con un disolvente como medio de reacción [28], dentro de los cuales la síntesis solvotermal es la más usada actualmente. Estos métodos tienen varías características en común: todos los componentes son disueltos en un disolvente, son mezclados y la solución permanece en equilibrio; de modo que, aún con los mismos componentes iniciales, cada método tendrá un producto final diferente [28]. Recientemente, se han explorado otras alternativas de síntesis en fase sólida, como la síntesis mecanoquímica, con el fin de reducir el tiempo de reacción y evitar el uso de disolventes [28][29]. 
Diferentes métodos pueden dar lugar a productos con tamaños de partícula, distribuciones y morfologías distintos, que se verán reflejadas en las propiedades del material. De allí la importancia de explorar diversos métodos de síntesis que se puedan ajustar a las características del material que se requiera [30].

El disolvente en el cual se sintetiza un PCP también tiene un rol importante en la estructura final, ya que las moléculas del mismo pueden co-cristalizar y de este modo incrementar las interacciones débiles de la estructura [18]. Por otro lado, las moléculas del disolvente pueden servir de patrón para la estructura, de modo que diferentes disolventes darán lugar a diferentes estructuras, aún con los mismos componentes iniciales [17]. A continuación, se describen los principales métodos de síntesis de PCPs.

\subsubsection{Síntesis solvotermal/hidrotermal}

Este método es bien conocido en la síntesis de zeolitas y ha sido adoptado y ampliamente utilizado para la síntesis de PCPs [17]. Se lleva a cabo en un recipiente cerrado bajo una presión autógena y por encima del punto de ebullición del disolvente utilizado [29]. Además se realiza en un rango de $80-260^{\circ} \mathrm{C}[31]$. En el caso de la síntesis solvotermal, normalmente se utilizan disolventes orgánicos con alto punto de ebullición o una mezcla de éstos, dentro de los disolventes más usados están la dimetilformamida, dietilformamida, acetonitrilo, acetona, etanol y metanol [29]; mientras que la síntesis hidrotermal se realiza en agua.

La reacción se realiza generalmente en tubos de presión para bajas temperaturas y en autoclaves de teflón para rangos por encima de $\sim 120^{\circ} \mathrm{C}{ }^{[29]}$. La diferencia en la solubilidad de los reactivos orgánicos e inorgánicos puede ser una barrera para la síntesis de PCPs. Sin embargo, en este método la solubilidad de los componentes puede verse favorecida según el disolvente utilizado, por lo que es una buena alternativa de síntesis [18]. Cabe señalar que puede ser considerado como un método lento al compararlo con otras opciones de síntesis, ya que su duración puede ser de horas a varios días [29].

\subsubsection{Síntesis asistida por microondas.}

En la síntesis de PCPs, el uso de microondas para aumentar la temperatura en una reacción solvotermal/hidrotermal ayuda a reducir el tiempo de cristalización de días a minutos (el tiempo de reacción raramente excede una hora [30]). Inclusive se han obtenido algunos materiales cuya síntesis era inalcanzable mediante el método solvotermal convencional [17]. Además, tiene las ventajas de poder mejorar la pureza del producto, seleccionar la fase requerida y controlar su morfología ${ }^{[30}$, 32]. El proceso se lleva a cabo por encima de los $100^{\circ} \mathrm{C}$ [30] y la calidad de los cristales obtenidos por este método es muy similar al solvotermal convencional [29]. 


\subsubsection{Síntesis electroquímica}

Su principal objetivo es el de excluir de la síntesis el uso de aniones como los nitratos, percloratos o clorhidratos para facilitar la producción a gran escala. En este método, la fuente metálica es una solución anódica en lugar de sales metálicas [32]. Los iones metálicos son introducidos al medio de reacción que contiene disueltos los ligantes orgánicos y una sal conductora. La deposición del metal en el cátodo es impedida con el uso de disolventes protónicos, aunque se genera $\mathrm{H}_{2}$ en el proceso [30]. Una ventaja de este método es la posibilidad de realizarlo en modo continuo y obtener mayores cantidades de producto, comparado con un método estacionario [30].

\subsubsection{Síntesis sonoquímica}

Esta síntesis utiliza la energía de la radiación ultrasónica $(20 \mathrm{kH}-10 \mathrm{kHz})$ para producir cambios físicos o químicos a los reactivos, mediante un proceso llamado cavitación [29]; el cual consiste en la formación, crecimiento y colapso instantáneo de burbujas en el líquido en el que se realiza la reacción. Esto provoca que la temperatura y la presión se eleven localmente (alrededor de $5000 \mathrm{~K}$ y 1000 bar [30]). Estas condiciones extremas pueden dar lugar a la ruptura de enlaces, formación de moléculas y radicales libres [30]. Este método tiene la ventaja de ser eficiente (desde el punto de vista energético), ecológico y de llevarse a cabo fácilmente a temperatura ambiente. Además, se realiza en un corto lapso de tiempo (de 30 a 180 minutos [29]), lo cual es una característica a considerar para la producción a gran escala [30].

\subsubsection{Síntesis mecanoquímica.}

La síntesis mecanoquímica se sirve de la fuerza mecánica para romper enlaces intermoleculares y producir un cambio químico [30]. Se realiza 'literalmente' moliendo los reactivos con un molino de bolas ${ }^{[10,33]}$. Este método presenta múltiples ventajas: se puede realizar a temperatura ambiente, no utiliza disolventes y los tiempos de reacción son cortos (de 10 a 60 minutos) [30]. En esta síntesis las sales metálicas pueden ser remplazadas por óxidos metálicos, lo que da lugar a agua como el único subproducto [30]. Una desventaja de este método es el tamaño de los cristales obtenidos: al ser microcristales se dificulta su posterior análisis estructural [28].

\subsection{Aplicaciones de PCPs}

Las propiedades antes mencionadas y la posibilidad casi infinita de combinaciones entre metales y ligantes abren un amplio abanico de posibles aplicaciones para estos materiales. A continuación, se describen de forma succinta las más relevantes hasta el momento. 


\subsubsection{Catálisis}

Actualmente, uno de los materiales utilizados comercialmente para catálisis son las zeolitas. Al poseer características similares a éstas (gran superficie interna y estructura porosa ordenada) [34], Ios PCPs han incursionado en el campo de la catálisis. Si bien los PCPs no compiten con las zeolitas en cuanto a estabilidad térmica y química, su composición orgánica e inorgánica ofrece una variedad de estructuras mucho más amplia. Esta versatilidad le da una ventaja por encima de otros materiales, ya que en principio es posible diseñar el sitio activo y el medio con buena precisión [35].

Los PCPs pueden funcionar como catalizadores mediante la presencia de centros metálicos insaturados, ligantes funcionalizados con grupos orgánicos o bien, con la incorporación de complejos metálicos al ligante [33], lo cual puede ser directamente durante la síntesis o mediante Modificación Post-Sintética (MPS) ${ }^{[35]}$.

El sistema de poros de los PCPs puede funcionar como el espacio físico en el cual las especies catalizadoras están encapsuladas o como el espacio donde se lleva a cabo la reacción [35]. En este último escenario, el PCP puede ser sólo espectador - participar en la reacción catalítica (estabilizando estados de transición, orientado moléculas o introduciendo sitios activos adicionales) [35].

\subsubsection{Biomedicina}

Una de las limitaciones de los medicamentos convencionales orales, es la imposibilidad de liberar de manera controlada el fármaco. Dos alternativas para este problema han sido utilizadas: sistemas de liberación orgánicos y sistemas de liberación inorgánicos. Los sistemas orgánicos tienen la ventaja de poder capturar diversos tipos de medicamentos y son altamente biocompatibles. A diferencia de los sistemas orgánicos, en los sistemas inorgánicos es posible controlar la tasa de liberación del medicamento, aunque su capacidad de almacenamiento es menor [36].

Al tener características híbridas y agrupar las características de los dos tipos de naturaleza mencionados anteriormente, los PCPs pueden ser utilizados para mecanismos de liberación controlada de fármacos. Los cationes metálicos más adecuados para ser utilizados en este tipo de aplicaciones son $\mathrm{Ca}^{+2}, \mathrm{Mg}^{+2}, \mathrm{Zn}^{+2}$, $\mathrm{Fe}^{+2}, \mathrm{Ti}^{+2} \mathrm{O} \mathrm{Zr}^{+2}$ [37]. En el caso de los ligantes, son preferidos aquellos con un carácter exógeno (naturales o sintéticos) que no intervengan con los procesos corporales [37]. Su principal desventaja es el tamaño de poro; al estar normalmente en el rango de microporos, la captura o el número de moléculas que pueden ser almacenadas se ve limitada [36].

De modo que se busca sintetizar PCPs con mesoporos para este tipo de aplicación. Horcajada et al. han utilizado dos PCPs mesoporosos para explorar la liberación 
controlada de ibuprofeno, MIL-100 y MIL-101 [38]. Los resultados obtenidos para el PCP MIL-100 fueron una adsorción de $0.34 \mathrm{~g}$ ibuprofeno/MIL-100 deshidratado con una liberación de 3 días. La adsorción para el PCP MIL-101 fue de 1.4 g/MIL-101 deshidratado con una liberación de 6 días.

\subsubsection{Separación y almacenamiento de gases}

En condiciones ambientales, las moléculas de los gases poseen una interacción intermolecular baja, lo cual representa un problema al momento de almacenarlas. En estas condiciones, los PCPs poseen diversas ventajas comparados con las zeolitas y los carbones activados, ya que el orden y la densidad de sus microporos favorecen el encapsulamiento; lo anterior se ve reflejado en una mejor captura ${ }^{[28]}$. Estas características sugieren entonces que los PCPs pueden ser utilizados para almacenar gases para diversas aplicaciones, como combustibles alternativos o la limpieza de la atmósfera.

EL primer estudio de adsorción de hidrógeno fue realizado en 2003 en el PCP MOF5, confirmando su potencial para almacenar $\mathrm{H}_{2}{ }^{[21]}$. En general, la funcionalidad de los ligantes orgánicos tiene una ligera influencia en la adsorción de $\mathrm{H}_{2}$, lo que ha llevado obtener mejores resultados es la construcción de PCPs con volúmenes de poro y áreas superficiales más grandes. Un ejemplo es el PCP de baja densidad NU100, el cual presenta una captura de $9 \%$ en peso a $77 \mathrm{~K}$ y 56 bar, este es el mejor valor reportado hasta el momento [21].

Otra opción para combustibles alternativos es el metano $\left(\mathrm{CH}_{4}\right)$, el primer estudio de adsorción de metano en un PCP a altas presiones fue reportado en el 2000. El PCP estudiado fue el CuSiF 6 (BPy) 2 con un valor de captura de $104 \mathrm{mg} \mathrm{g}^{-1}$ a 36 atm y 298 $K{ }^{[21]}$. Similar a la estrategia para una mayor captura de $\mathrm{H}_{2}$, en el caso del metano también se busca sintetizar PCP con mayor espacio, tal es el caso del PCP MOF210, con una capacidad de adsorción de $476 \mathrm{mg} \mathrm{g}^{-1}$ a 80 bar y $298 \mathrm{~K}^{[21]}$.

Los PCPs también son una opción para evitar la acumulación de $\mathrm{CO}_{2}$ en la atmósfera. En 2005, un estudio detallado de la adsorción de $\mathrm{CO}_{2}$ en el material MOF-177 mostró que su capacidad de adsorción era de $1470 \mathrm{mg} \mathrm{g}^{-1}$. En su momento, era un valor que excedía cualquier valor reportado por otro material [21]. Actualmente, el valor más alto de captura de $\mathrm{CO}_{2}$ a altas presiones lo tiene el PCP MOF-200 (2437 $\mathrm{mg} \mathrm{g}^{-1}$ a 50 bar y 278 K) [21]. 


\section{ANTECEDENTES}

\subsection{Reacciones de acoplamiento}

\subsubsection{Perspectiva histórica}

Un método ampliamente usado para para la formación de enlaces $\mathrm{C}-\mathrm{C}, \mathrm{C}-\mathrm{H}, \mathrm{C}$ - O, C - S, C - P o C - M son las reacciones de acoplamiento, proceso en el que intervienen reactivos organometálicos $\left(R^{1}-m\right)$ con electrófilos orgánicos $\left(R^{2}-X\right)$ catalizados por complejos de metales de transición (M) (Esquema 2-1). [39, 40]

Las reacciones para formar enlaces $\mathrm{C}-\mathrm{C}$ mediante paladio iniciaron con el trabajo pionero reportado por Tsuji en 1965[4]]. Una mezcla de un complejo de $\mathrm{PdCl}_{2-}$ (cicloctadieno) y etil malonato en condiciones básicas generó de manera exitosa el producto de carbopaladación a temperatura ambiente. Posteriormente, Tsuji investigó la reacción del complejo m-alil paladio

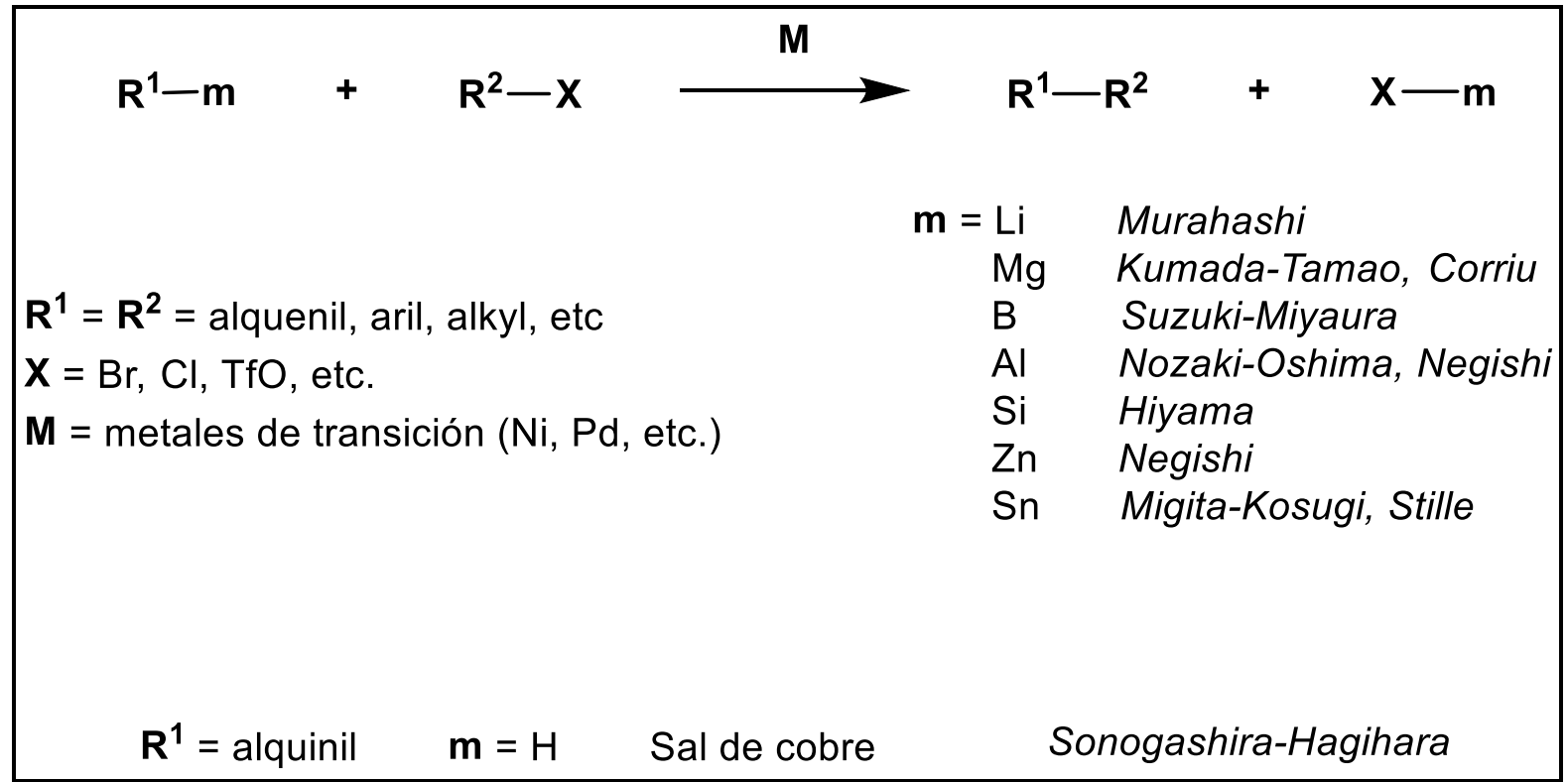

Esquema 2-1. Reacciones de acoplamiento más representativas.[39] 


\subsubsection{Ciclo catalítico}

El ciclo inicia con la especie $\operatorname{LnPd}(0)$ catalíticamente activa, donde $\mathrm{L}$ representa un ligando. En ocasiones, en lugar de $\mathrm{Pd}(0)$ es posible usar $\mathrm{Pd}(\mathrm{II})$ el cual es reducido in situ, lo que lo hace menos reactivo. Sin embargo, la mayor estabilidad de los Pd(II), comparados con aquellos de $\mathrm{Pd}(0)$, le proporciona una ventaja. ${ }^{[42]}$

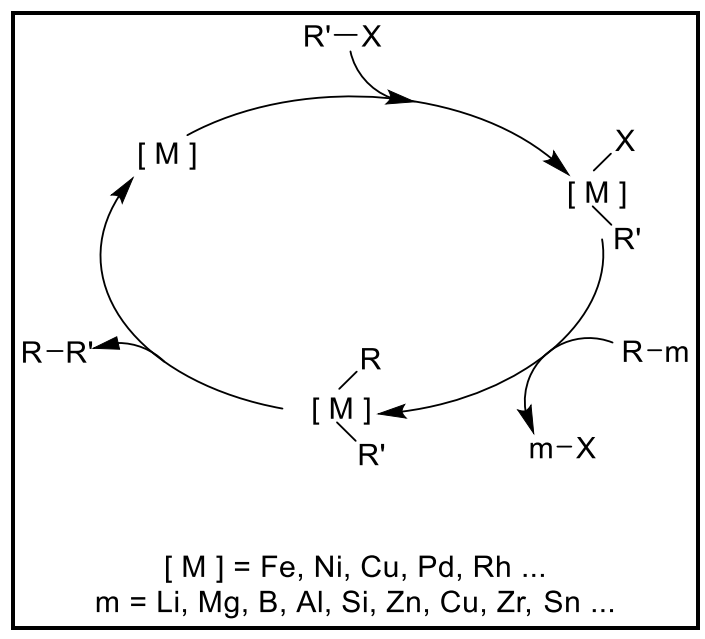

Esquema 2-2. Ciclo catalítico general de las reacciones de acoplamiento.[40]

\subsection{Acoplamiento Suzuki-Miyaura}

La reacción de acoplamiento Suzuki-Miyaura involucra a un ácido borónico, un éster borónico o cualquier especie de boronato y un haluro de alilo en presencia de un catalizador de paladio (0)

El éxito de esta reacción reside en el hecho de que funciona con un amplio rango de sustratos y con una alta tolerancia de grupos funcionales. ${ }^{[42]}$ 


\section{OBJETIVOS}

- General

Sintetizar ligantes bi- y tetracarboxilados que puedan utilizarse como precursores para la síntesis de nuevos PCPs.

- PARTICULARES

- Sintetizar los precursores de los ligantes mediante reacciones de acoplamiento Suzuki-Miyaura y/o mediante reacciones de acoplamiento Sonogashira.

- Caracterizar los compuestos sintetizados mediante Espectrometría de masas, Resonancia Magnética Nuclear y Espectroscopía Infrarrojo.

A continuación, se muestran los compuestos a sintetizar.

- Nuevos ligantes que puedan ser utilizados para preparar nuevos PCPs. 
L1

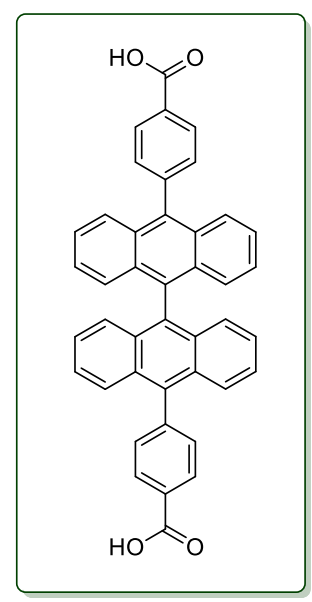

L2

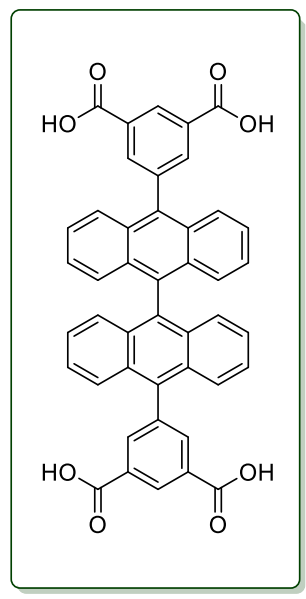

L3

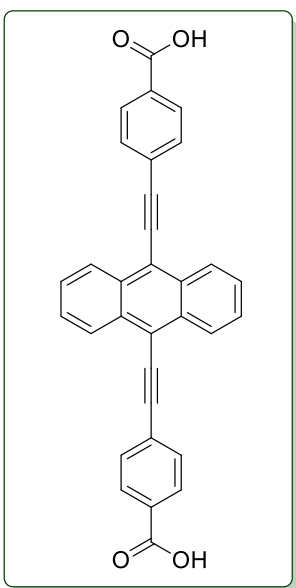

L5

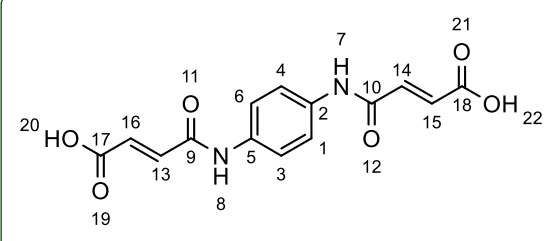

- Utilizar ligantes previamente reportados para la síntesis de nuevos PCPs.

L4

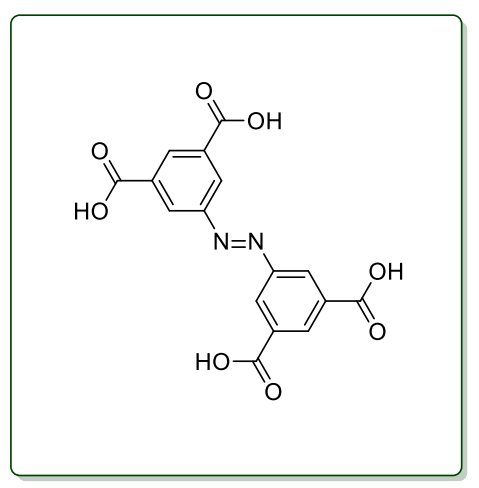




\section{RESULTADOS Y DISCUSIÓN}

\subsection{Moléculas previas}

Para aprender el método de síntesis de acoplamientos biarilo mediante el Acoplamiento Suzuki-Miyaura, se inició con la síntesis de un ligante reportado en una tesis previa (P1).

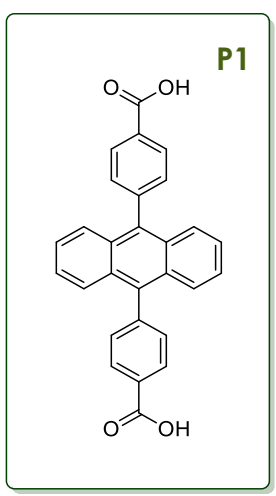

El siguiente esquema muestra las condiciones de síntesis reportadas:

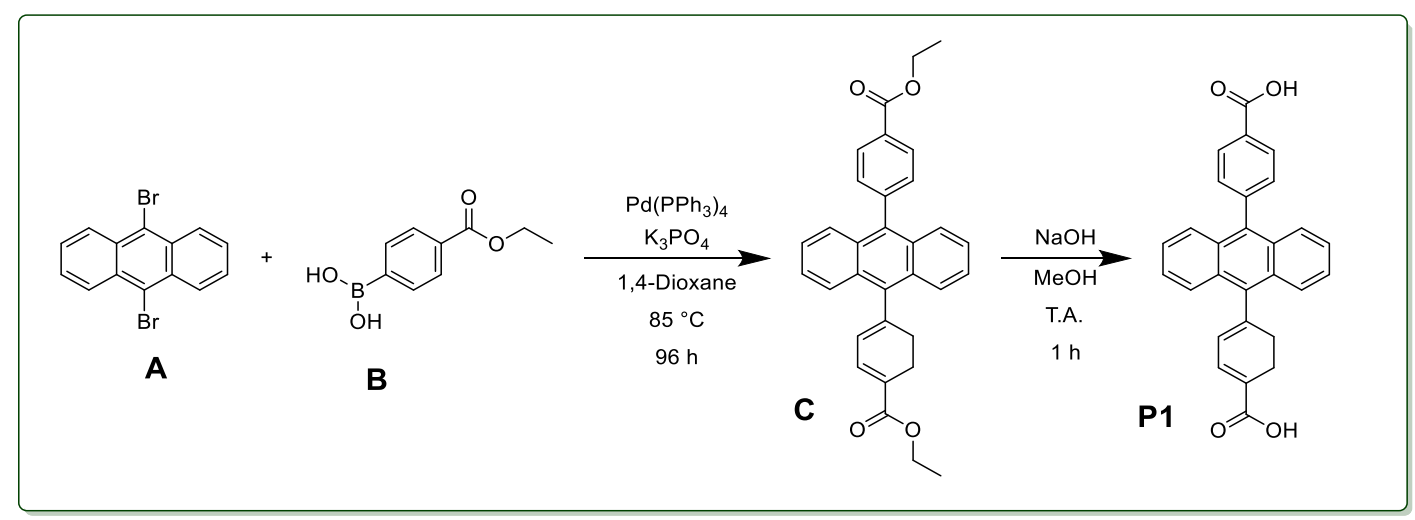

Esquema 4-1. Síntesis del ligante P1.

En nuestro caso, el acoplamiento Suzuki no dio el compuesto deseado, por lo que se modificaron las condiciones de síntesis para obtener el precursor $\mathbf{C}$; si bien el producto fue obtenido con un rendimiento bajo, se logró caracterizar el producto. 


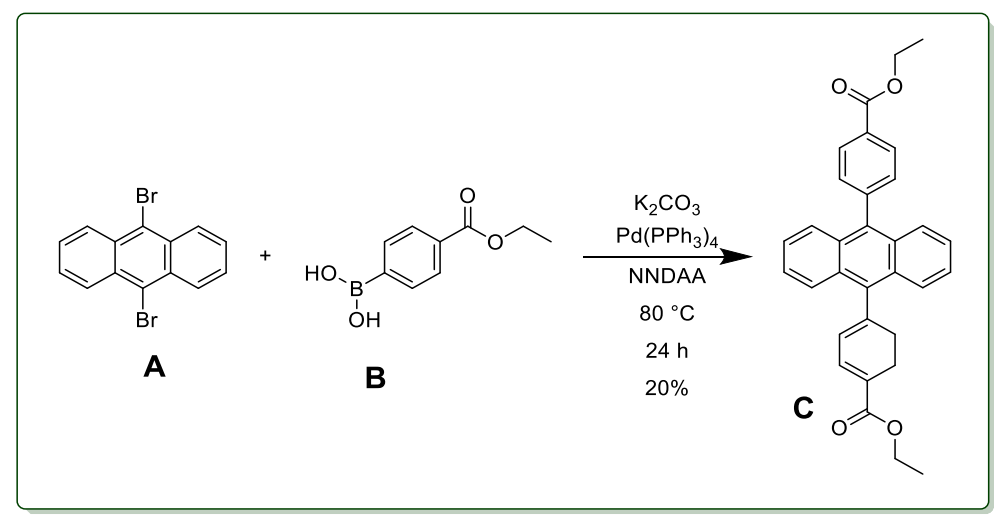

Esquema 4-2. Síntesis del precursor $\mathbf{C}$.

Por otro lado, y previo a intentar la hidrólisis del esquema 4-1 para obtener P1, se intentó hacer el acoplamiento en un solo paso, utilizando un ácido borónico distinto. El método con el que obtuvimos el compuesto Pl está descrito en el Esquema 4-3.

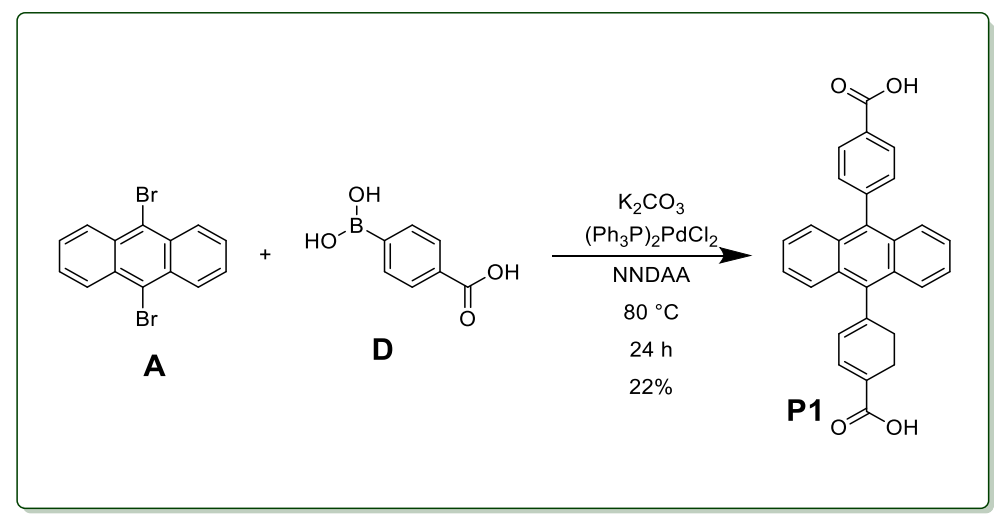

Esquema 4-3. Síntesis del ligante P1 en un solo paso.

Una vez más, el rendimiento fue bajo. Sin embargo, se logró obtener el ligante P1 en un solo paso y con un tratamiento del producto final mínimo. Los intentos de obtener el ligante $\mathrm{Pl}$ nos dieron la pauta del camino a seguir para obtener las moléculas objetivo. 


\subsection{Ligante L1}

Para la síntesis de este ligante (compuesto 3) se propuso utilizar una reacción de acoplamiento Suzuki-Miyaura, bajo tres condiciones distintas: variando el disolvente y la temperatura (Esquema 4-4).

En la Tabla 4-1 se detallan las condiciones de cada experimento.

\begin{tabular}{|c|c|c|c|}
\hline EXPERIMENTO & $\mathbf{A}$ & B & C \\
\hline $\begin{array}{l}\text { REACTIVO A } \\
(1 \text { eq) }\end{array}$ & $\begin{array}{c}50 \mathrm{mg} \\
97.6 \mu \mathrm{mol}\end{array}$ & $\begin{array}{l}50 \mathrm{mg} \\
97.6 \mu \mathrm{mol}\end{array}$ & $\begin{array}{l}50 \mathrm{mg} \\
97.6 \cdot \mu \mathrm{mol}\end{array}$ \\
\hline $\begin{array}{l}\text { REACTIVO B } \\
(2.2 \text { eq) }\end{array}$ & $\begin{array}{c}35.6 \mathrm{mg} \\
0.21 \mathrm{mmol}\end{array}$ & $\begin{array}{c}35.6 \mathrm{mg} \\
0.21 \mathrm{mmol}\end{array}$ & $\begin{array}{c}35.6 \mathrm{mg} \\
0.21 \mathrm{mmol}\end{array}$ \\
\hline $\mathrm{K}_{2} \mathrm{CO}_{3}$ & $\begin{array}{c}135 \mathrm{mg} \\
0.97 \mathrm{mmol}, 10 \mathrm{eq}\end{array}$ & $\begin{array}{c}135 \mathrm{mg} \\
0.97 \mathrm{mmol}, 10 \mathrm{eq}\end{array}$ & $\begin{array}{c}202 \mathrm{mg} \\
1.46 \mathrm{mmol}, 15 \mathrm{eq}\end{array}$ \\
\hline $\begin{array}{l}\text { CATALIZADOR } \\
(0.20 \mathrm{eq})\end{array}$ & $\begin{array}{c}\left(\mathbf{P h}_{3} \mathbf{P}\right) \mathbf{P d C l}_{2} \\
13.7 \mathrm{mg} \\
19.5 \mathrm{\mu mol}\end{array}$ & $\begin{array}{c}\left(\mathbf{P h}_{3} \mathbf{P}\right) \mathbf{P d C l} \mathbf{P d}_{2} \\
13.7 \mathrm{mg} \\
19.5 \mu \mathrm{mol}\end{array}$ & $\begin{array}{c}\mathbf{P d}\left(\mathbf{P P h}_{3}\right)_{4} \\
16.9 \mathrm{mg} \\
19.5 \mu \mathrm{mol}\end{array}$ \\
\hline DISOLVENTE & $\begin{array}{l}\text { NNDAA } \\
(20 \mathrm{ml})\end{array}$ & $\begin{array}{c}\mathrm{H}_{2} \mathrm{O} / \mathrm{CH}_{3} \mathrm{CN} \\
20 \mathrm{ml}(1: 1 \mathrm{v} / \mathrm{v})\end{array}$ & $\begin{array}{l}\text { DMF } \\
10 \mathrm{ml}\end{array}$ \\
\hline RENDIMIENTO & / & / & $20-25 \%$ \\
\hline
\end{tabular}

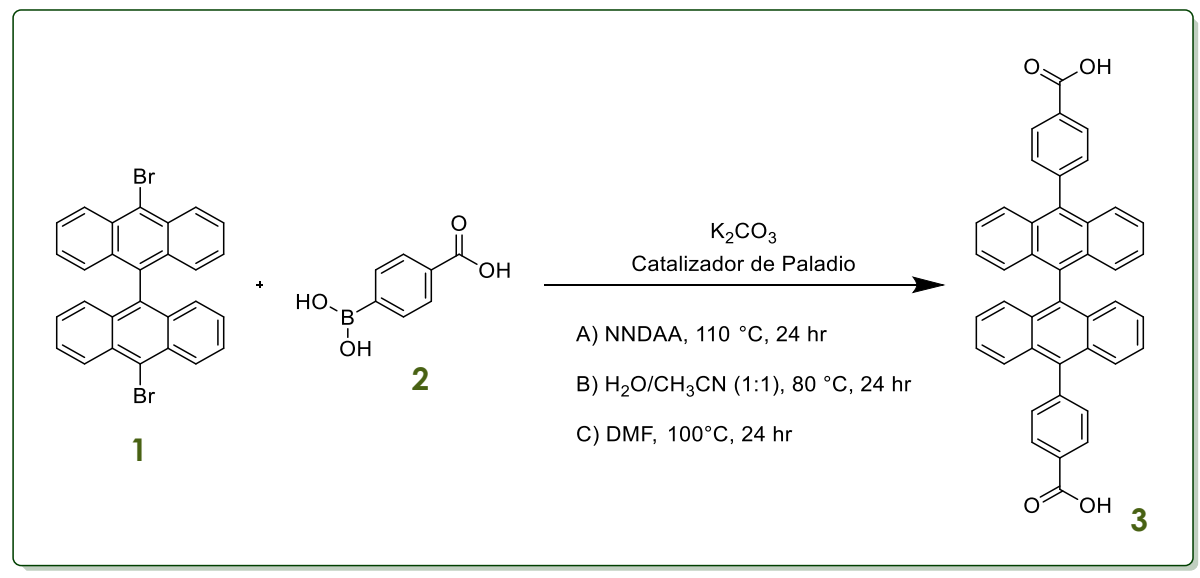

Esquema 4-4. Síntesis del ligante dicarboxilado 3 (L1). 
Los experimentos A y B no dieron los resultados obtenidos, mientras que con el experimento $\mathrm{C}$ obtuimos el ligante deseado.

En la sección de Metodología experimental se encuentran los detalles del espectro del ligante L 1 .

\subsection{Ligante $L 2$}

Para la síntesis del ligante L2 (compuesto 5), se utilizó nuevamente un acoplamiento Suzuki (Esquema 4-5).

Previo a esta reacción, se inició con la síntesis de (4), siguiendo el método reportado por Lin y colaboradores ${ }^{[43]}$. (Esquema 3-3)

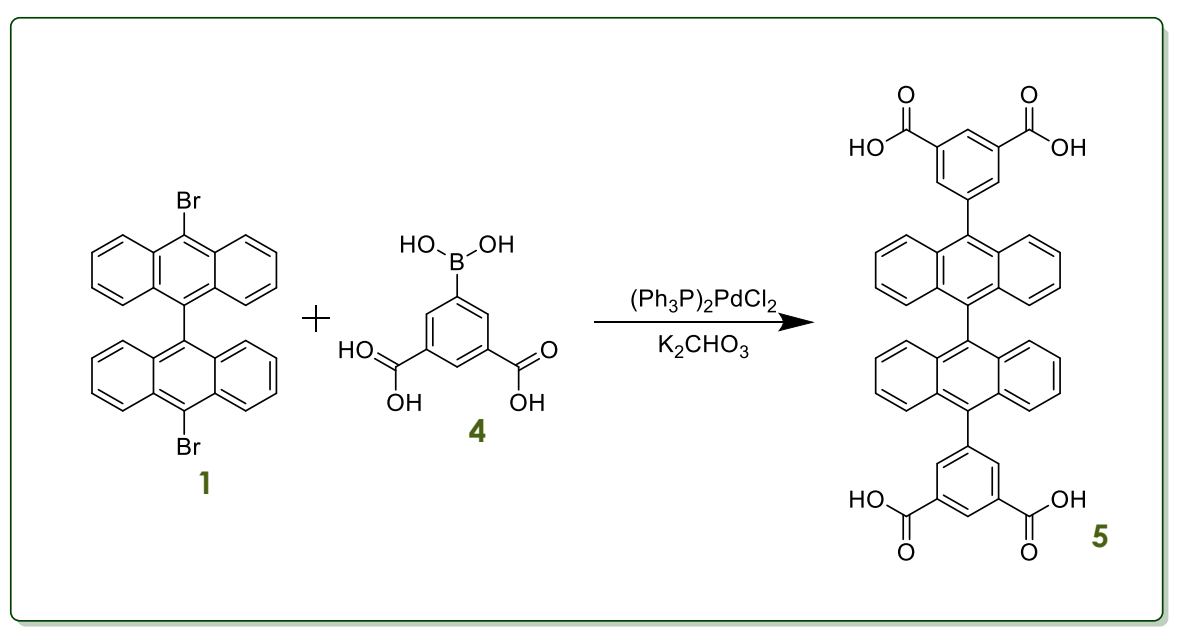

Esquema 4-5. Síntesis del ligante tetracarboxilado 5 (L2). 


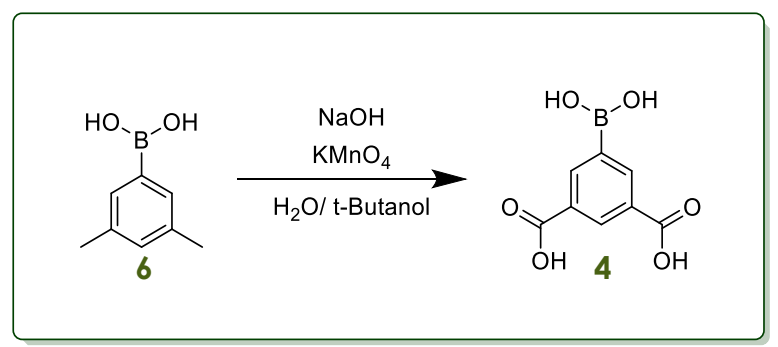

Esquema 4-6. Síntesis del compuesto 4.

En el caso de la reacción de oxidación (Esquema 3-3), la reacción se llevó acabo en múltiples ocasiones, modificando y combinando dos métodos previamente reportados por $M$. Schröder y colaboradores ${ }^{[33]}$. Aun siguiendo las indicaciones descritas en tales reportes no se obtuvieron los rendimientos reportados en cada caso. Nuestros rendimientos rondaron entre 20 y $30 \%$. De forma adicional, resultó difícil caracterizar el ácido borónico bi-carboxílico (4), no fue sino hasta después de varios intentos de síntesis que se logró obtener un espectro de protón de RMN.

Una forma indirecta de determinar si se obtuvo el producto deseado es a través del éster (7) a partir de (4) mediante la reacción propuesta en el Esquema 4-7. Además de que este éster podría ser acoplado a (1) e hidrolizado en un paso posterior, para obtener L2.

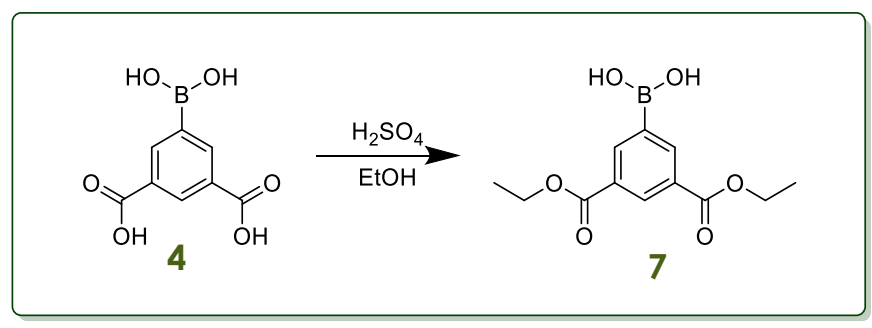

Esquema 4-7. Síntesis del compuesto 7.

Se obtuvo y se logró caracterizar el compuesto 7, aunque con rendimientos bajos, entre 30 y $40 \%$.

Posteriormente se procedió a la síntesis de L2 por dos métodos, el acoplamiento de 1 y el ácido carboxílico (Esquema 4-5. Síntesis del ligante tetracarboxilado 5 (L2).Esquema 4-5) y mediante el acoplamiento de 1 con el éster, seguido de una hidrólisis para obtener L2 (Esquema 4-8). 


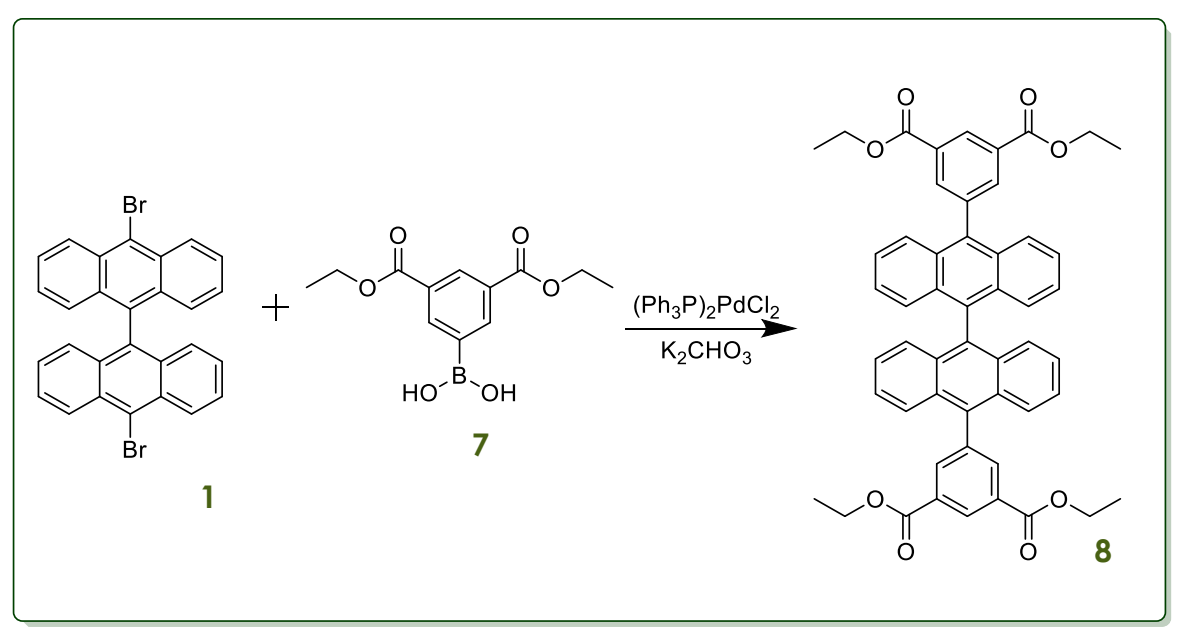

Esquema 4-8. Síntesis del precursor (8) para la síntesis del ligante tetracarboxilado 5 (L2).

En ambos casos no se lograron obtener los productos deseados.

\subsection{Ligante $\mathrm{L} 3$}

La síntesis del ligante L3 inició con la obtención del compuesto (11), a partir del método reportado por Zhu y colaboradores [44] (acoplamiento Sonogashira, Esquema 4-9).

Se logró la síntesis y la caracterización del precursor (11) con un rendimiento de alrededor del $80 \%$.

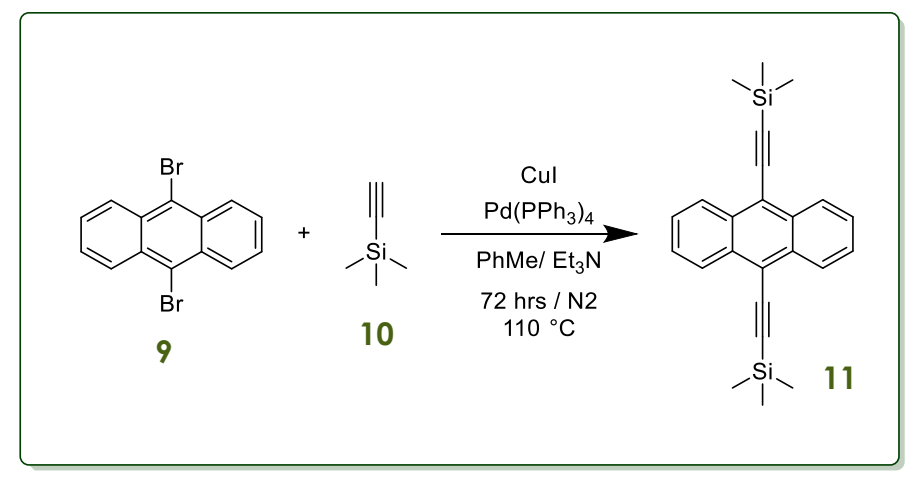

Esquema 4-9. Síntesis del compuesto 10. 
El paso siguiente fue hidrolizar el compuesto (11) siguiendo el método descrito por Zhu ${ }^{[44]}$ (Esquema 4-10), y así obtener un precursor del ligante L3.

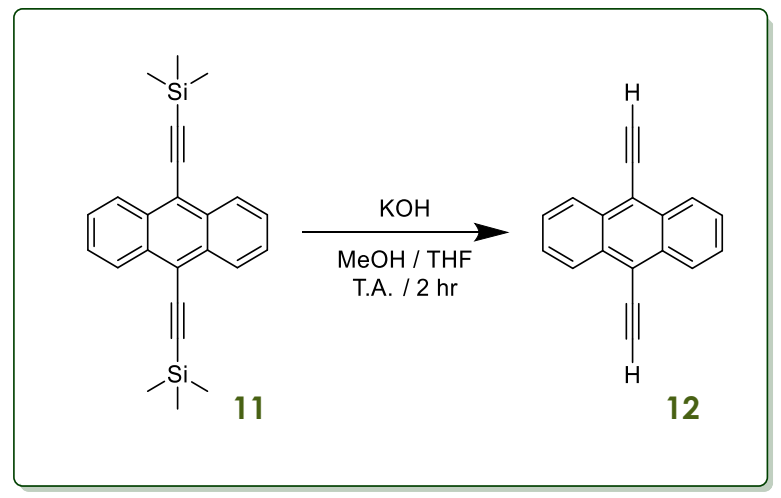

Esquema 4-10. Síntesis del compuesto 11.

\subsection{Ligante L4}

Para la síntesis del ligante L4 (14) se propuso utilizar el método descrito por Wang y colaboradores [45]. (Esquema 4-11)

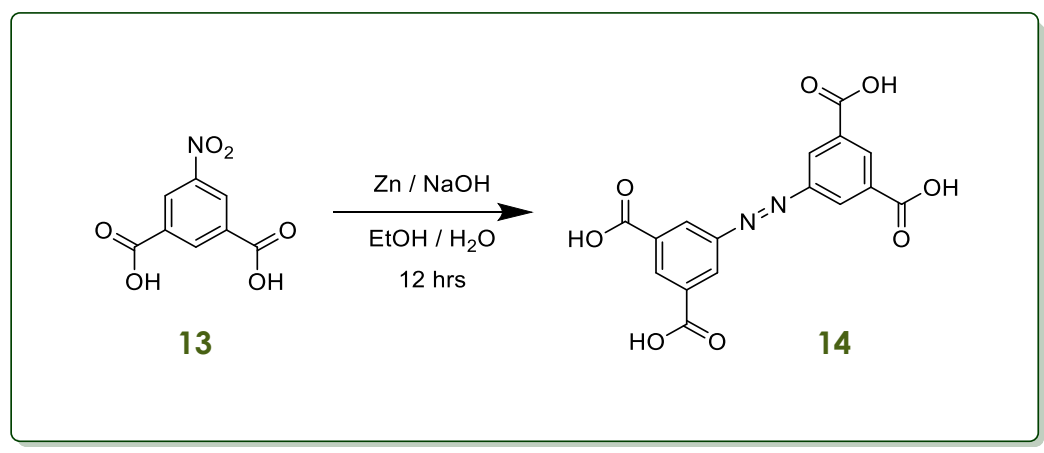

Esquema 4-11. Síntesis del compuesto L3.

Este ligante ya ha sido sintetizado y utilizado como precursor de otros PCPs previamente reportados. Sin embargo, se realizó con éxito la síntesis de este compuesto, con el objetivo de aprender la metodología para la síntesis de otros compuestos con enlace azo que puedan utilizarse como precursores de PCPs. Es importante mencionar que estos primeros intentos son pioneros en México para la síntesis de ligantes basados en el grupo azo. 
Este lígate fue utilizado en colaboración con el grupo de investigación del Dr. llich Argel Ibarra en el Instituto de Materiales de la UNAM para el estudio de un PCP ya reportado. A este material, se le realizaron pruebas de captura de $\mathrm{CO}_{2}$ en condiciones de humedad relativa.

Al momento de la realización de esta tesis, los resultados de ese estudio no han sido reportados. La Figura 4-1 muestra una parte de los resultados obtenidos hasta el momento por el grupo del Dr. Ibarra.
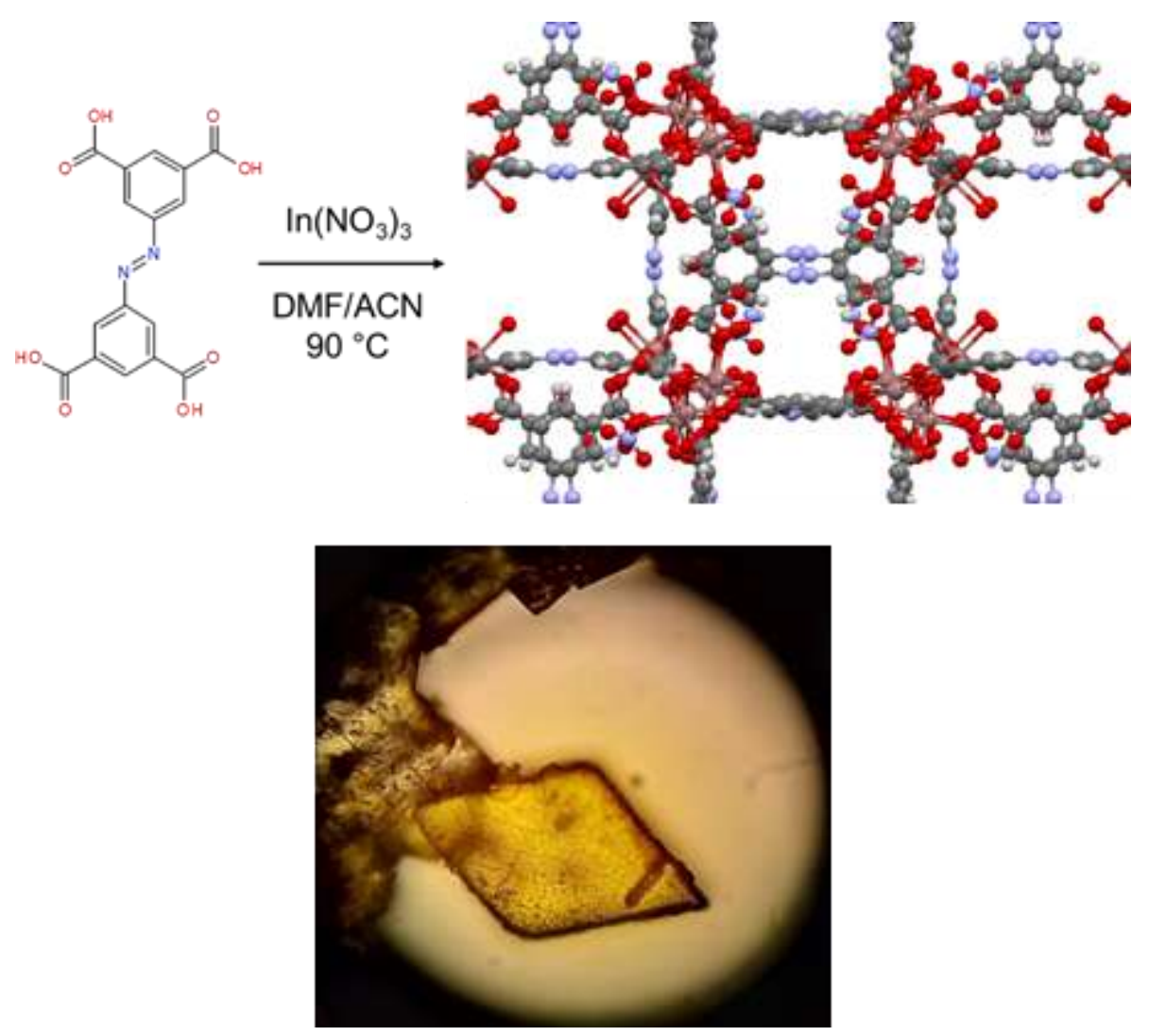

Figura 4-1. (arriba) Síntesis y estructura del PCP obtenido con el ligante L4. (abajo) Vista al microscopio de uno de los cristales del PCP obtenidos (artículo en redacción).

\subsection{Ligante L5}

Dentro del grupo de investigación se han utilizado compuestos de la familia de las maleimidas. Al estar a nuestra disposición la dimaleimida (15), se propuso la apertura de los anillos para obtener el ligante L5. 


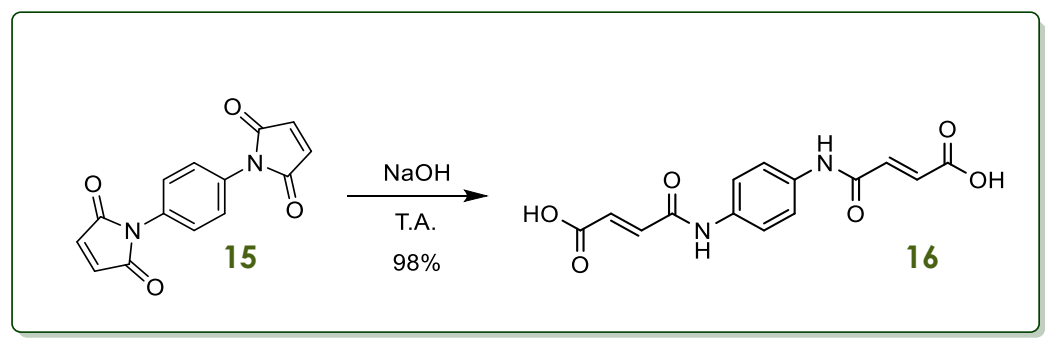

Esquema 4-12. Síntesis del ligante L5

La reacción procedió sin ningún contratiempo y en cantidades cuantitativas.

Este ligante fue enviado a un grupo de investigación en la Universidad de Adelaide en Australia para la síntesis de un nuevo material PCP. 


\section{CONCLUSIONES Y PERSPECTIVAS}

Se logró la síntesis y caracterización de un ligante como precursor de PCPs y la síntesis y caracterización de 3 precursores más.

Si bien los rendimientos y no todas las reacciones dieron los resultados esperados, se exploraron los métodos de acoplamiento más utilizados en la síntesis de este tipo de ligantes.

El siguiente paso consistirá en utilizar estos ligantes en combinación con iones metálicos para la síntesis de nuevos PCPs y explorar las posibles aplicaciones que puedan tener, por ejemplo, para captura de $\mathrm{CO}_{2}$ y $\mathrm{SO}_{2}$. 


\section{PARTE EXPERIMENTAL}

Los reactivos utilizados fueron adquiridos en Sigma-Aldrich-Merck. Los disolventes no fueron sometidos a ningún proceso de purificación o secado.

Las reacciones se llevaron a cabo bajo calentamiento térmico/solvotermal usando baños de aceite mineral y matraces de vidrio tipo bola equipados con agitadores magnéticos y sistemas a reflujo.

Para el monitoreo del avance de las reacciones, se utilizó cromatografía de capa fina (TLC), usando como fase estacionaria placas de sílice-gel soportado en aluminio con indicador de fluorescencia. Para el revelado de las placas se utilizó una lampara UV (double band 254/365 nm).

Para la caracterización de los compuestos se utilizaron las siguientes técnicas y los equipos correspondientes:

\section{i. Puntos de fusión}

Los puntos de fusión de los sólidos obtenidos fueron determinados en un aparato tipo Fisher de la marca Electrothermal 9200, los valores obtenidos se reportan sin corrección.

\section{ii. Espectros de Infarrojo}

Se determinaron los espectros IR con un equipo de espectrofotometría de infrarrojo Perkin Elmer Spectrum 2000 (FT-IR/ATR).

\section{iii. $\quad$ H-RMN y ${ }^{13} \mathrm{C}-\mathrm{RMN}$}

Para la adquisición de los espectros de RMN se utilizó un equipo de $500 \mathrm{MHz}$ Bruker modelo AMX (Avance III). El disolvente utilizado fue DMSO-d6 y TMS como referencia interna. Los desplazamientos químicos $(\delta)$ se reportan en partes por millón (ppm) y las constantes de acoplamiento en Hertz (Hz). Las multiplicidades se expresan como señal simple (s), señal doble (d), señal doble de dobles (dd), señal triple (†), señal cuadruple (c) y señal múltilple como (m).

\section{iv. Espectroscopia de masas}

Los espectros de masas se determinaron haciendo uso de un equipo de espectrofotometría de masas de alta resolución (HRMS) (MicroTOF \|| Bruker) mediante ionización por electroespray (ESI-MS). 


\subsection{Dietil 4,4'-(antracen-9,10-dii) dibenzoato (Compuesto C).}

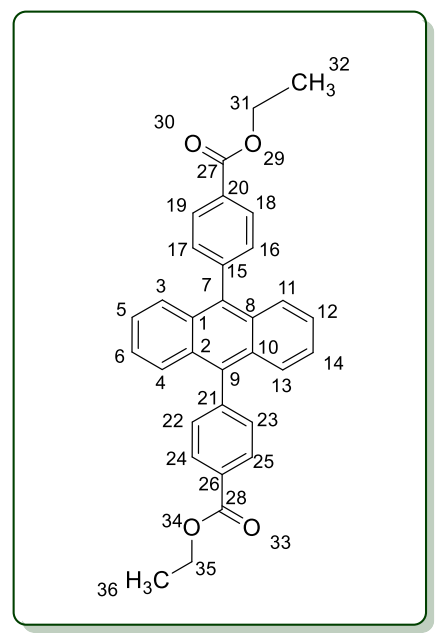

En un matraz bola de dos bocas equipado con un agitador magnético se colocaron 9,10-dibromobiantraceno, etinil 4-boronobenzoto y carbonato de potasio $\left(\mathrm{K}_{2} \mathrm{CO}_{3}\right.$ ), los cuales fueron disueltos en NNDAA. Purgamos la mezcla con Ar, colocamos el matraz en un montaje a reflujo y purgamos nuevamente durante 30 minutos. Después, agregamos el catalizador de paladio y purgamos 20 minutos más. Al finalizar la purga, calentamos hasta llegar a la temperatura deseada (80 $\left.{ }^{\circ} \mathrm{C}\right)$. Finalizado el tiempo de reacción (24 h), se comprobó la ausencia del reactivo limitante (9,10-dibromobiantraceno) mediante TLC con una fase móvil de Hex:AcOE† (3:1 v/v). Posteriormente, se dejó enfriar la reacción a TA, se agregó una solución de bicarbonato de sodio, se filtró para quitar los restos del catalizador y se realizó una extracción con acetato de etilo. La fase orgánica fue secada con sulfato de sodio anhidro y posteriormente fue concetrada. Finalmente se realizó una purificación en columna con una fase móvil Hex:AcOEł (97:3). 


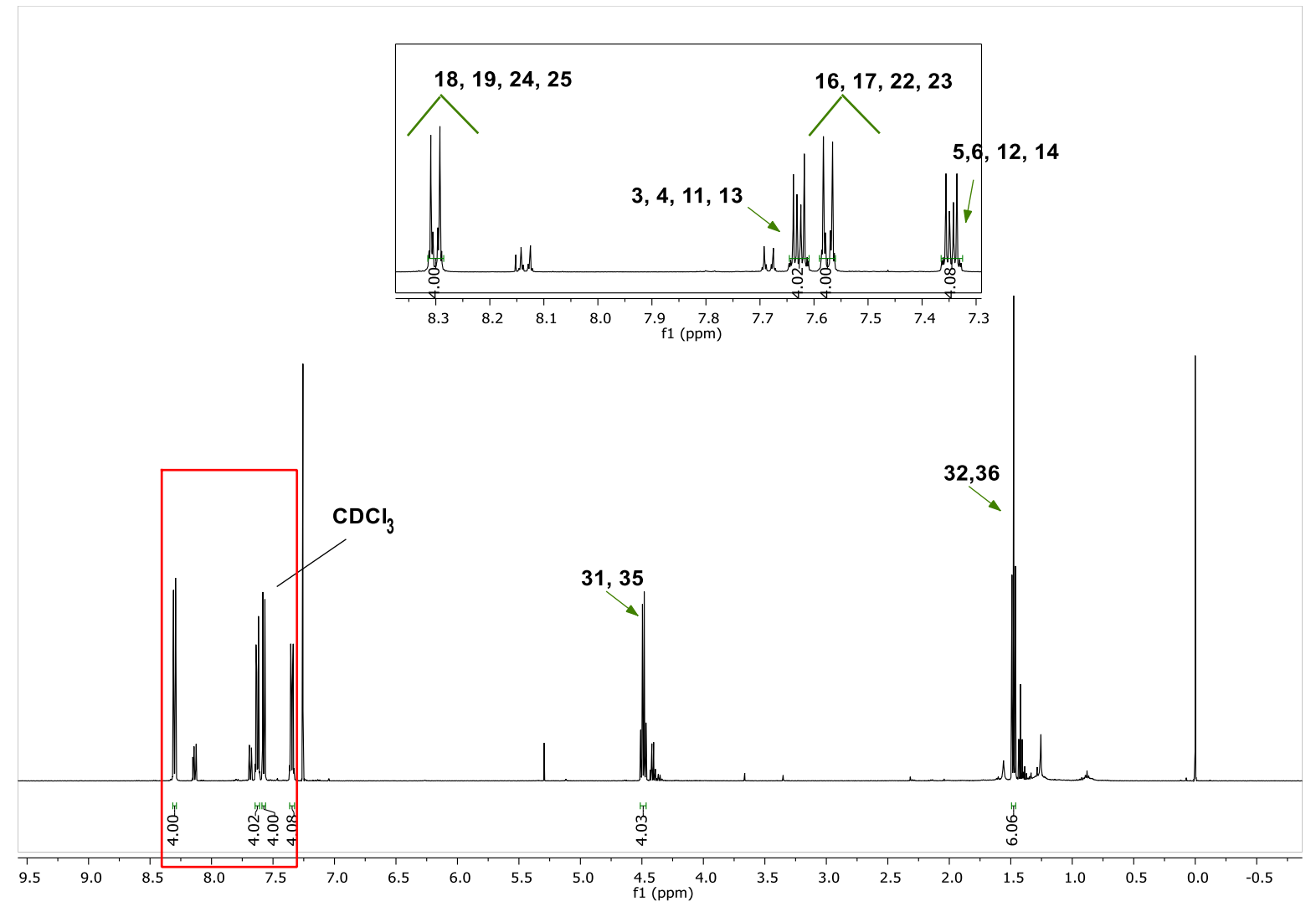

Figura 6-1. Espectro de ${ }^{1} \mathrm{H}-\mathrm{RMN}$ del compuesto (C). 


\section{2. Ácido 4,4'-(antraceno-9,10-diil)dibenzoico (P1)}

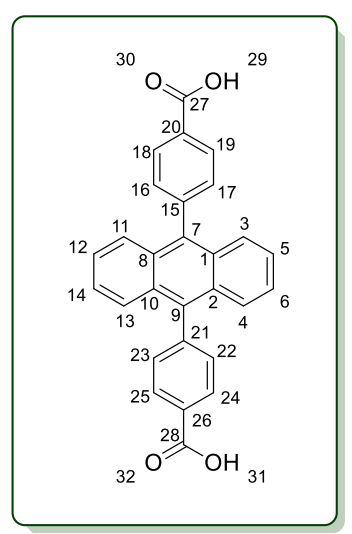

En un matraz bola de dos bocas equipado con un agitador magnético se colocaron 9, 10-dibromoantraceno, ácido 4-borobenzoico y carbonato de potasio $\left(\mathrm{K}_{2} \mathrm{CO}_{3}\right)$, los cuales fueron disueltos en NNDAA. Purgamos la mezcla con Ar, colocamos el matraz en un montaje a reflujo y purgamos nuevamente durante 30 minutos. Después, agregamos el catalizador de paladio y purgamos 20 minutos más. Al finalizar la purga, calentamos hasta llegar a la temperatura deseada (80 $\left.{ }^{\circ} \mathrm{C}\right)$. Finalizado el tiempo de reacción (24 h), se comprobó la ausencia del reactivo limitante (9,10-dibromoantraceno) mediante TLC con una fase móvil de Hex:AcOE† $(1: 1 \mathrm{v} / \mathrm{v})$, observando que el producto permanecía en el punto de aplicación. Posteriormente, se dejó enfriar la reacción a TA, se agregó agua destilada y se filtró la solución para quitar los restos del catalizador. Finalmente se realizó una extracción con AcOEł y agua destilada y se acidificó la fase acuosa con $\mathrm{HCl}$ hasta tener $\mathrm{pH}$ 1. En cada caso se formó un precipitado que fue recuperado por filtración y lavado con agua destilada. 


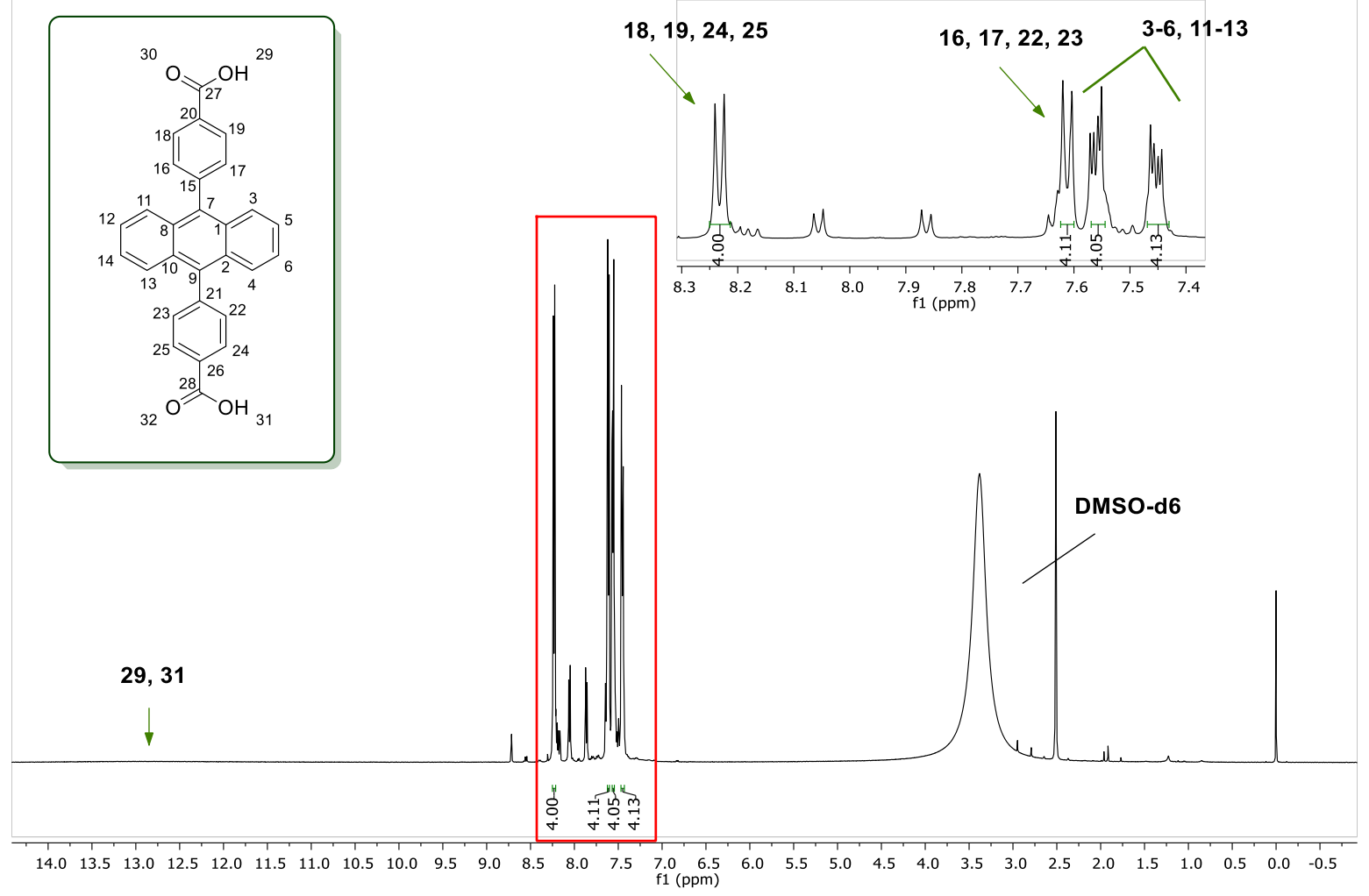

Figura 6-2. Espectro de ${ }^{1} \mathrm{H}-\mathrm{RMN}$ del ligante $\mathrm{Pl}$. 


\section{3. Ácido dibenzoico (L1)

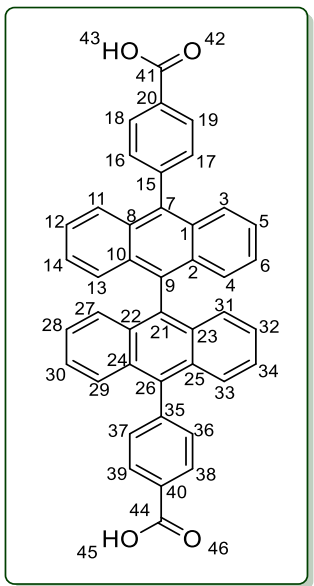

En un matraz bola de dos bocas equipado con un agitador magnético se colocaron 10,10'-dibromo-9-9'-biantraceno), ácido 4-borobenzoico y carbonato de potasio $\left(\mathrm{K}_{2} \mathrm{CO}_{3}\right)$, los cuales fueron disueltos en NNDAA para el método $A$, en una mezcla 1:1 de agua destilada, acetonitrilo para el método $B$ y en DMF para el método C. Purgamos la mezcla con $\mathrm{N}_{2}$, colocamos el matraz en un montaje a reflujo y purgamos nuevamente durante 30 minutos. Después, agregamos el catalizador de paladio y purgamos 20 minutos más. Al finalizar la purga, calentamos hasta llegar a la temperatura deseada. Finalizado el tiempo de reacción ( $24 \mathrm{~h}$ para cada método), se comprobó la ausencia del reactivo limitante (10,10'-dibromo-99'-biantraceno) mediante TLC con una fase móvil de Hex:AcOEł (1:1 v/v), observando que el producto permanecía en el punto de aplicación. Posteriormente, se dejó enfriar la reacción a TA, se agregó agua destilada y se filtró la solución para quitar los restos del catalizador. Finalmente se realizó una extracción con AcOEł y agua destilada y se acidificó la fase acuosa con $\mathrm{HCl}$ hasta tener $\mathrm{pH} 1$. En cada caso se formó un precipitado que fue recuperado por filtración y lavado con agua destilada.

- 'H-NMR (500 MHz, DMSO-d 6 ): $\delta 13.11$ (s br, 2H, H-43, H-45), 8.30 (d, 4H, J = $8.1 \mathrm{~Hz}, \mathrm{H}-3, \mathrm{H}-11, \mathrm{H}-29, \mathrm{H}-33$ ), 7.79 (d, 4H, J = 8.2 Hz, H-4, H-13, H-27, H-31), $7.69(\mathrm{~d}, 4 \mathrm{H}, \mathrm{J}=8.9 \mathrm{~Hz}, \mathrm{H}-5, \mathrm{H}-12, \mathrm{H}-30, \mathrm{H}-34), 7.44$ (ddd, $4 \mathrm{H}, \mathrm{J}=8.9,6.4,1.3$ $\mathrm{Hz}, \mathrm{H}-18, \mathrm{H}-19, \mathrm{H}-38, \mathrm{H}-39$ ), 7.28 (ddd, $4 \mathrm{H}, \mathrm{J}=8.9,6.4,1.3 \mathrm{~Hz}, \mathrm{H}-16, \mathrm{H}-17, \mathrm{H}-$ 36, H-37), 7.10 (d, 4H, J = 8.8 Hz, H-6, H-14, H-29, H-33).

- P.F.: $>250^{\circ} \mathrm{C}$ 


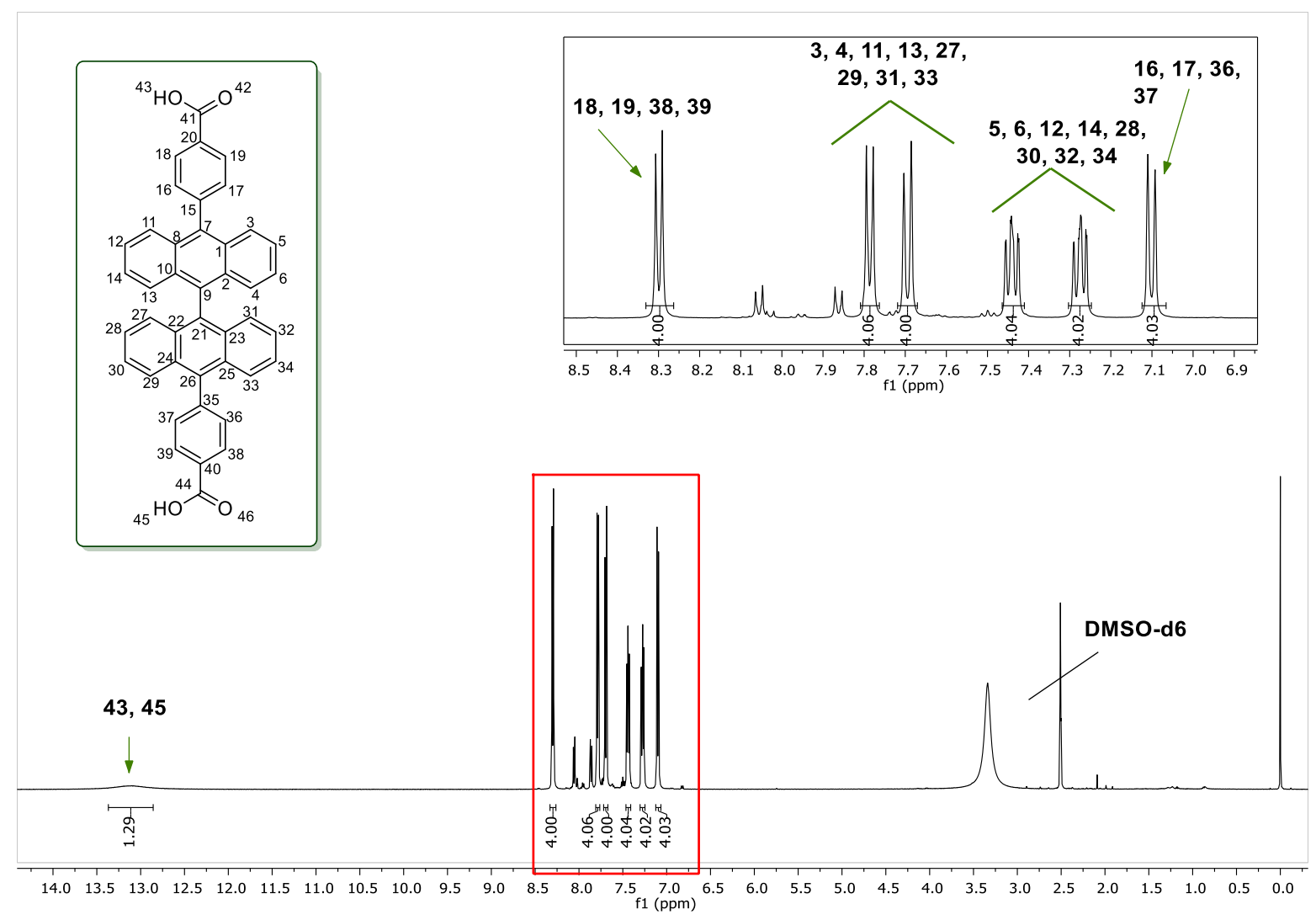

Figura 6-3. Espectro de ${ }^{1} \mathrm{H}-\mathrm{RMN}$ del ligante L1 . 


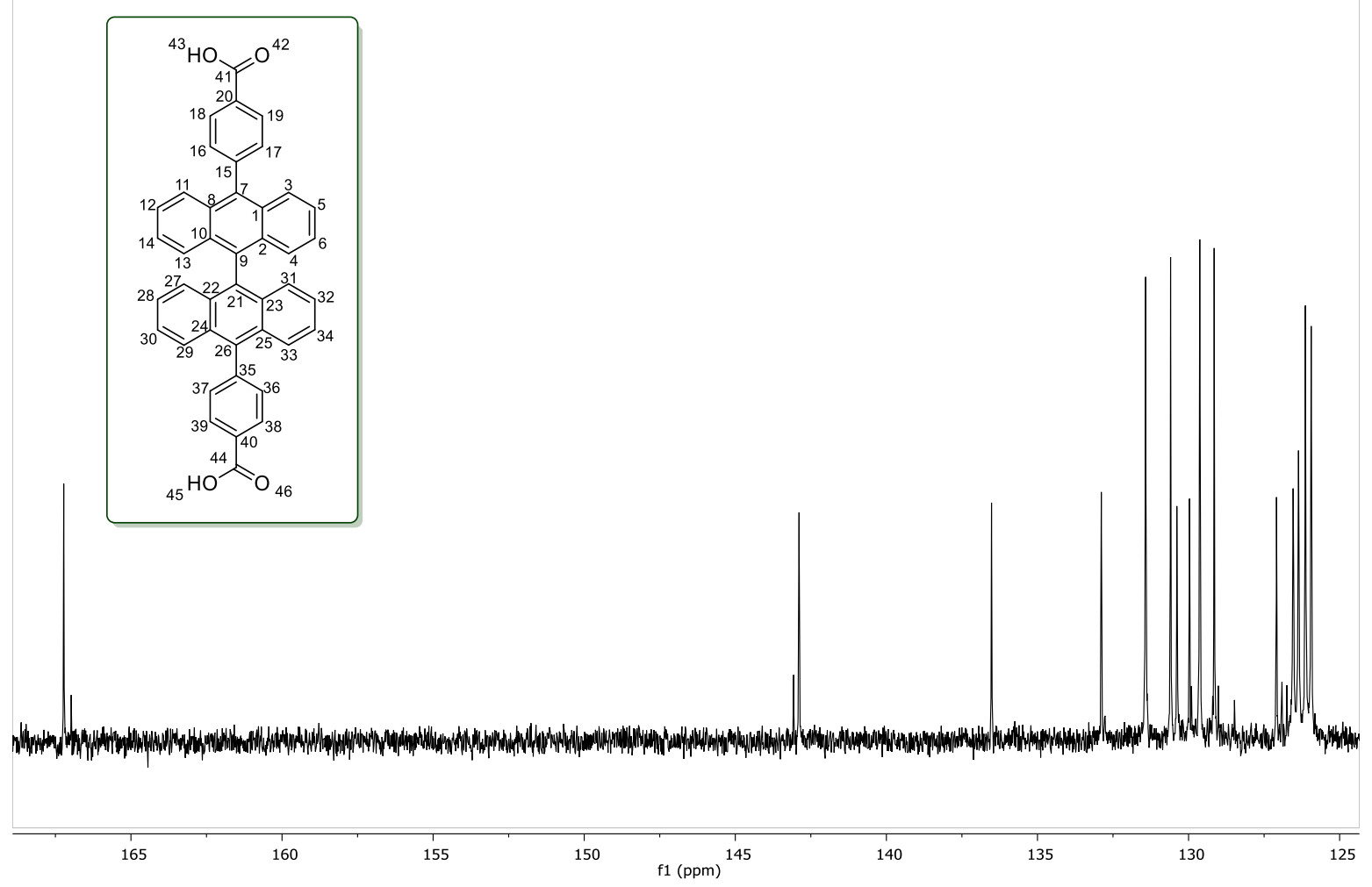

Figura 6-4. Espectro de ${ }^{13} \mathrm{C}-\mathrm{RMN}$ del ligante L1 . 


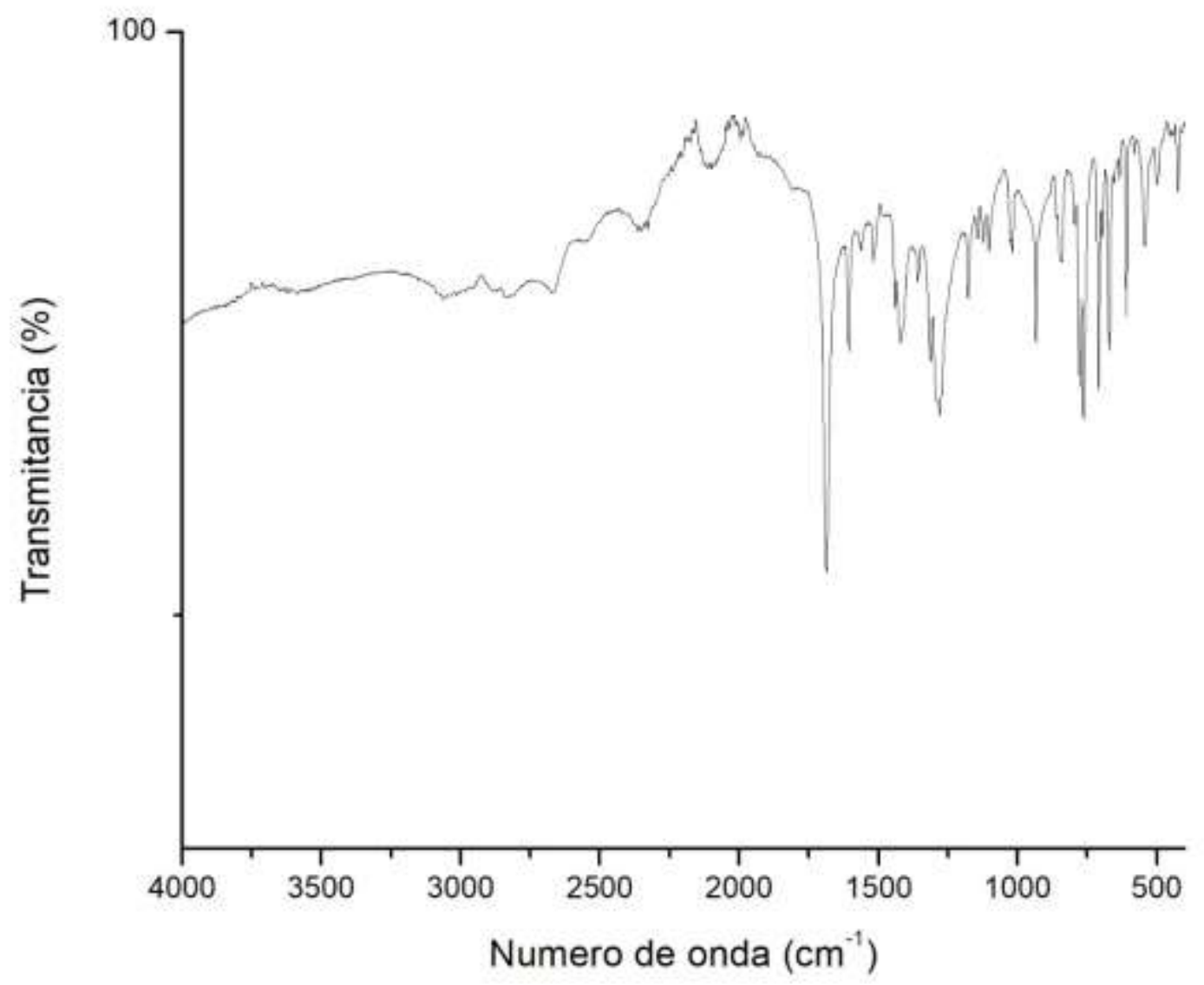

Figura 6-5. Espectro de FTIR-ATR del ligante L1. 


\section{4. Ácido 5-boronoisoftálico (Compuesto 4)}

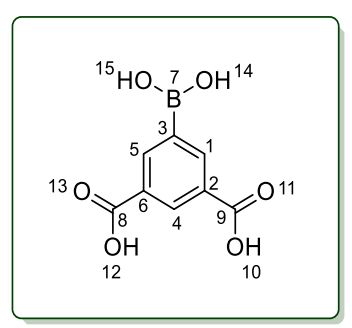

En un matraz bola de dos bocas equipado con un agitador magnético se disolvió ácido 3,5-dimetilborónico junto con el $\mathrm{NaOH}$ en una mezcla de agua/tert-butanol ( $\vee / \vee ~ 1: 1)$. Se calentó la mezcla a $50^{\circ} \mathrm{C}$ y se agregó permanganato de potasio $\left(\mathrm{KMnO}_{4}\right.$ ) en pequeñas cantidades de manera paulatina (cuando el color púrpura se ha desvanecido es momento de agregar nuevamente una pequeña cantidad de $\mathrm{KMNO}_{4}$ ). Una vez que se agregaron 4.7 equivalentes de $\mathrm{KMnO}_{4}$, se aumentó la temperatura a $70{ }^{\circ} \mathrm{C}$ y seguimos agregando $\mathrm{KMnO}_{4}$, hasta que el color púrpura permaneció por más de 3h. Posteriormente, se redujo el exceso de $\mathrm{KMnO}_{4}$ con tiosulfato de sodio $\left(\mathrm{Na}_{2} \mathrm{~S}_{2} \mathrm{O}_{3}\right.$ ) (se observó el desvanecimiento del color morado) y se filtró la solución aúOn estando caliente. Los restos del óxido de manganeso formado fueron lavados con un exceso de agua destilada caliente. Después, se concentró el agua del filtrado (para obtener $\sim 100 \mathrm{ml}$ ) y se acidificó con $\mathrm{HCl}$ hasta tener $\mathrm{pH}$ 1. Finalmente, se filtró para obtener un sólido beige/blanco el cual fue lavado con agua destilada y secado a TA. Rendimiento $30 \%$.

- $\quad$ H-NMR (500 MHz, DMSO- $\left.\mathrm{d}_{6}\right): \delta 8.49$ ( $\left.\mathrm{td}, 2 \mathrm{H}, \mathrm{J}=1.8,0.6 \mathrm{~Hz}, \mathrm{H}-4\right), 8.17$ (dd, $2 \mathrm{H}$, $J=7.7,1.8 \mathrm{~Hz}, \mathrm{H}-1, \mathrm{H}-5)$

- ${ }^{13}$ C-RMN (125 MHz, DMSO-d6): $\delta 166.6$ (C-8, C-9), 133.5 (C-1, C-5), 131.2 (C-3), 130.5 (C-4), 129.9 (C-2, C-6).

- P.F.: $>250^{\circ} \mathrm{C}$ 


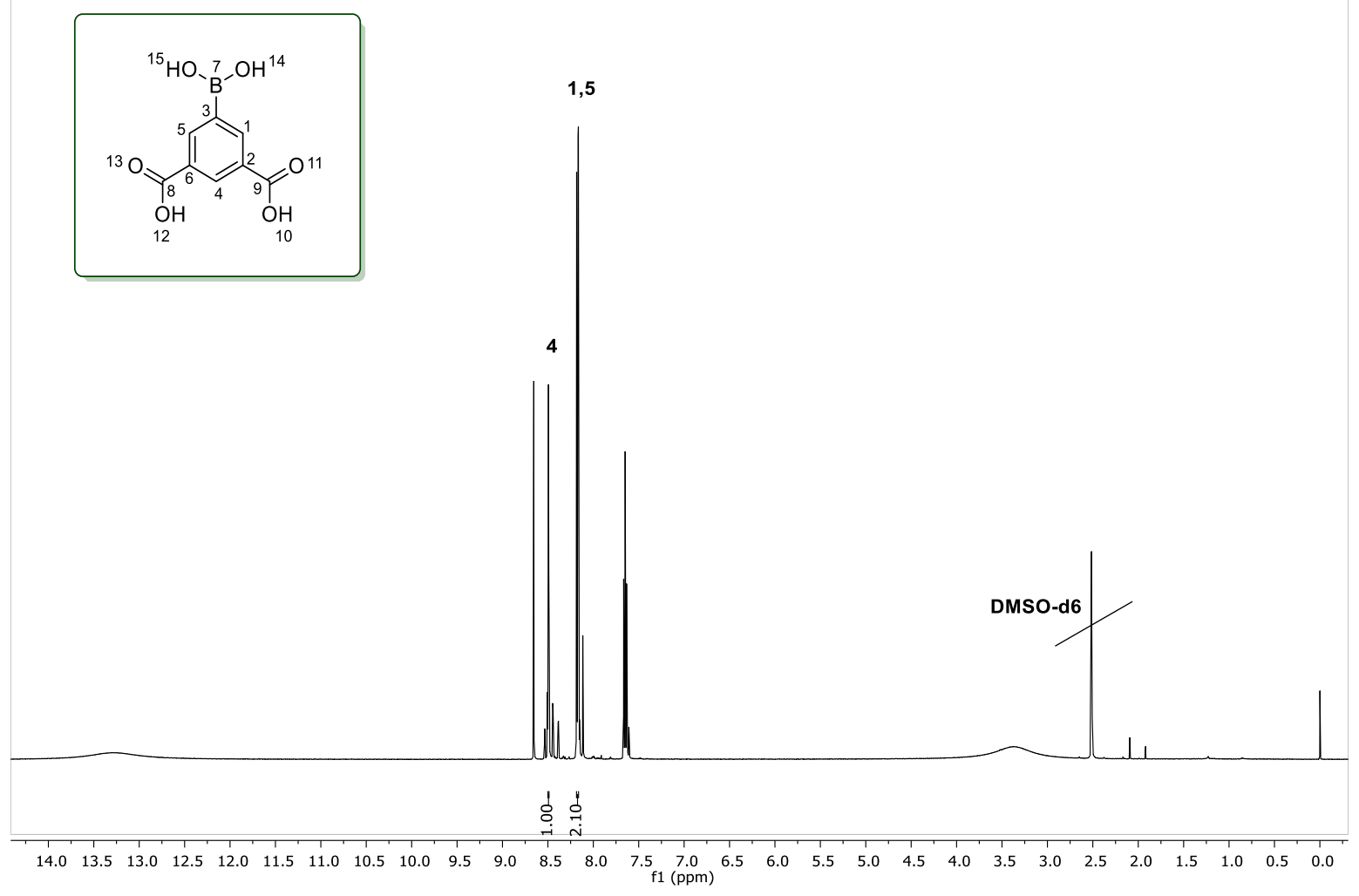

Figura 6-6. Espectro de ${ }^{1} \mathrm{H}-\mathrm{RMN}$ del Compuesto 4. 


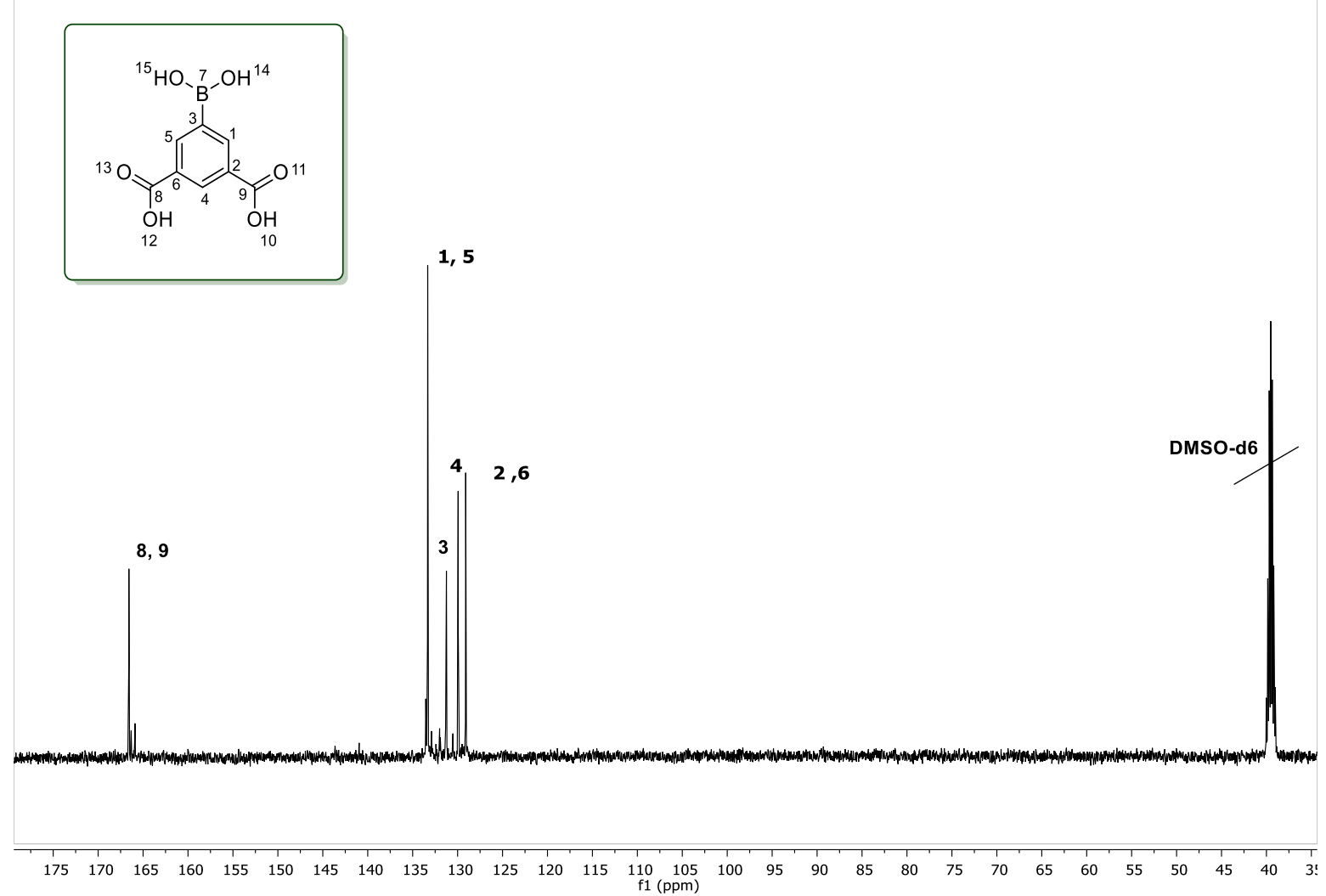

Figura 6-7. Espectro de ${ }^{13} \mathrm{C}$-RMN del Compuesto 4. 


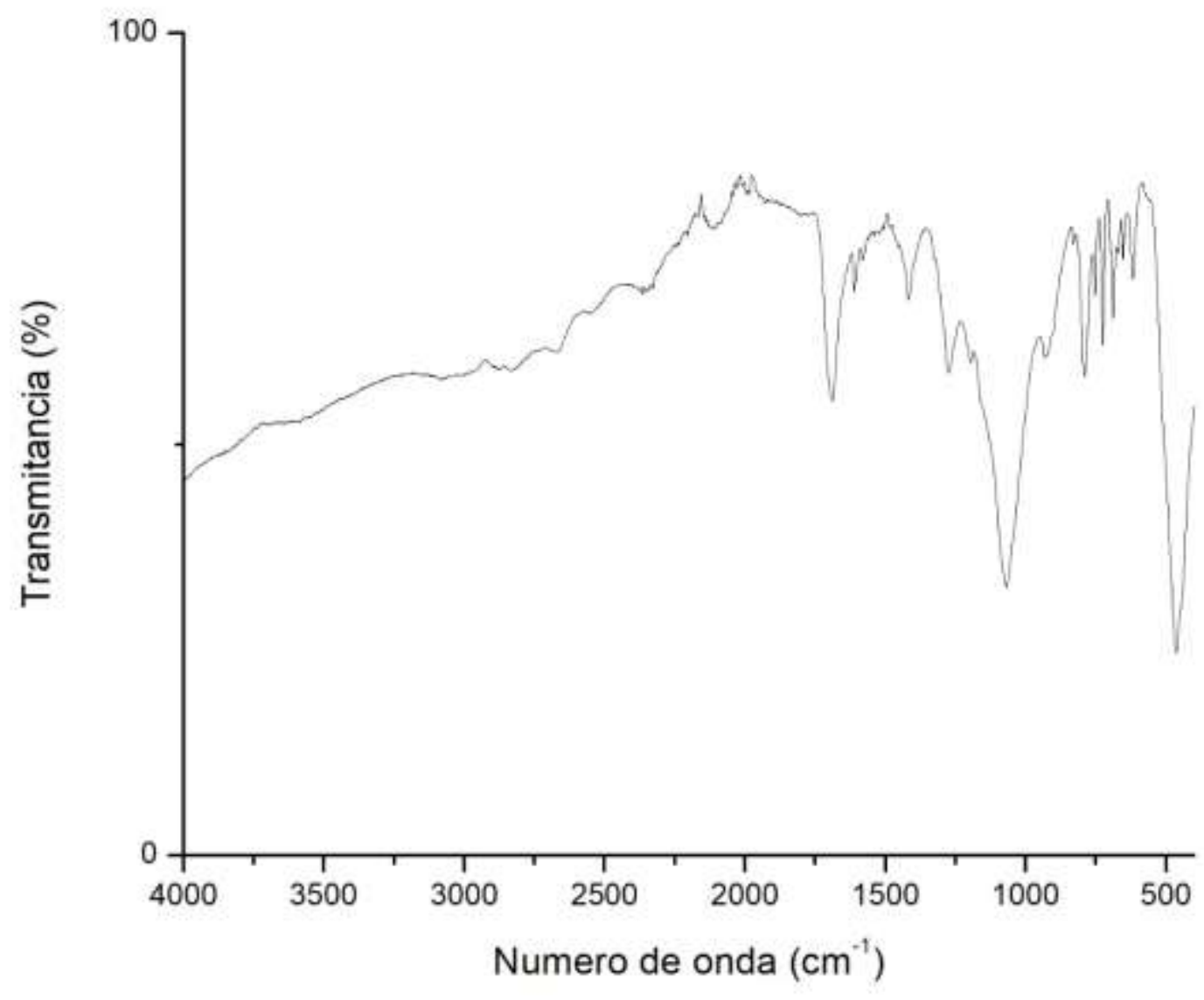

Figura 6-8. Espectro de FTIR-ATR del Compuesto 4. 


\section{5. Ácido (3,5-bis(etoxicarbonil)fenil) borónico (Compuesto 7)}

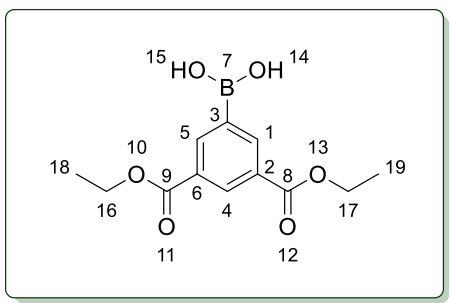

En un matraz de dos bocas de $10 \mathrm{ml}$ equipado con un agitador magnético $20 \mathrm{mg}$ del compuesto 4 (9.52 mol) fueron disueltos en $2 \mathrm{ml}$ de EłOH y mezclados con $7 \mu \mathrm{l}$ de $\mathrm{H}_{2} \mathrm{SO}_{4}$ (98\%). La solución fue calentada a reflujo durante 12h. Al finalizar ese tiempo, se le agregaron $5 \mathrm{ml}$ de agua destilada, formándose un precipitado blanco. Se recuperó el producto mediante filtración, se lavó con agua destilada y se dejó secar a TA.

- ${ }^{H} \mathrm{H}-\mathrm{NMR}\left(500 \mathrm{MHz}, \mathrm{CDCl}_{3}\right): \delta 8.72(\mathrm{t}, 1 \mathrm{H}, J=1.6 \mathrm{~Hz}, \mathrm{H}-4), 8.50(\mathrm{~d}, 2 \mathrm{H}, J=1.6 \mathrm{~Hz}$, $\mathrm{H}-1, \mathrm{H}-5), 4.47$ (d, 2H, J = 7.1 Hz, H-16, H-17), 1.45 (s, 3H, H-18, H-19).

- P.F.: $110^{\circ} \mathrm{C}$ 


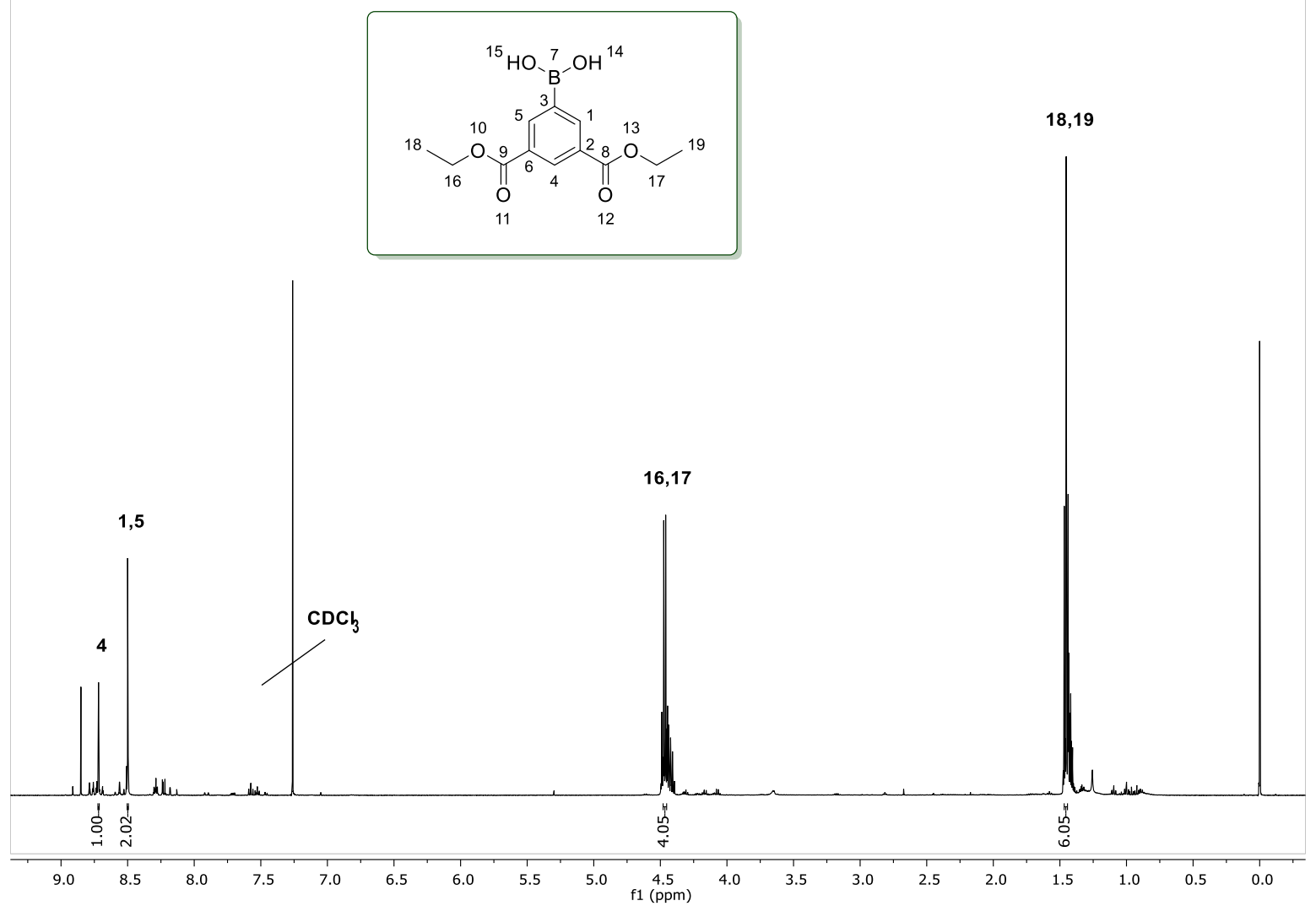

Figura 6-9. Espectro de ${ }^{1} \mathrm{H}-\mathrm{RMN}$ del Compuesto 7. 


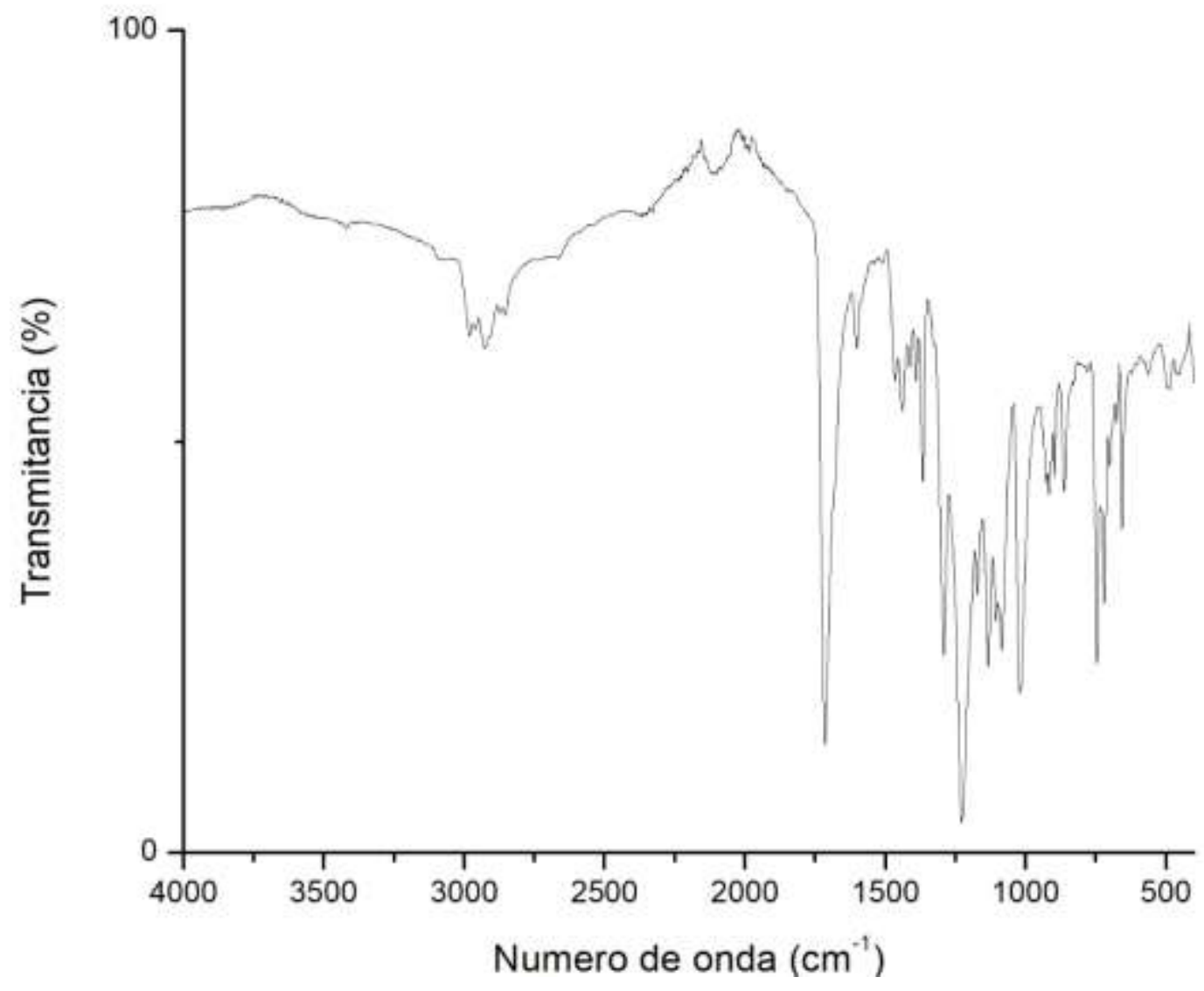

Figura 6-10. Espectro de FTIR-ATR del Compuesto 7. 


\subsection{9,10-bis ((trimetil silil)etinil)antraceno (Compuesto}

10)

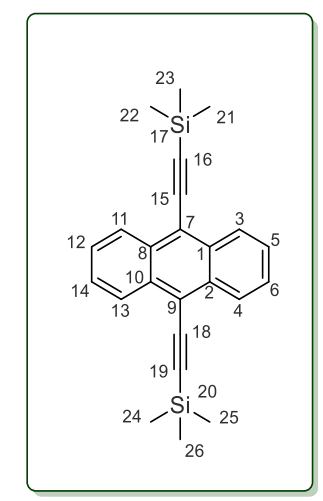

En un matraz de dos bocas de $250 \mathrm{ml}$ equipado con un agitador magnético, se disolvieron $200 \mathrm{mg}$ de 9,10 dibromoantraceno en $50 \mathrm{ml}$ de una solución de PhMe y $\mathrm{Et}_{3} \mathrm{~N}$ ( $\mathrm{v} / \mathrm{v}$ 8:2). Posteriormente se agregaron $0.336 \mathrm{ml}$ de etiniltrimetisilano, se colocó el matraz en un montaje a reflujo y se purgó la mezcla con $\mathrm{N}_{2}$, durante 30 minutos aproximadamente. Transcurrido ese tiempo, se agregaron los catalizadores Cul $(11.3 \mathrm{mg}$ ) y tetrakis(trifenilfosfina) de paladio (0) $(68.8 \mathrm{mg})$ y se purgó el montaje nuevamente. Posteriormente se calentó la mezcla de reacción a $110^{\circ} \mathrm{C}$. Después de 72 horas de reacción, se confirmó la ausencia del reactivo limitante $(9,10$ dibromoantraceno) mediante TLC. Se dejó enfriar la reacción a TA y el solvente fue evaporado en el rotavapor. Se le agregó agua destilada a la mezcla resultante y fue extraída con diclorometano. Finalmente se realizó una purificación mediante una columna de cromatografía con Hex como eluyente, para finalmente obtener 188 mg de un sólido rojo ( $85 \%$ de rendimiento).

- 'H-NMR (500 MHz, CDCl $)$ ): $\delta 8.59-8.55(\mathrm{~m}, 4 \mathrm{H}, \mathrm{H}-3, \mathrm{H}-4, \mathrm{H}-11, \mathrm{H}-13), 7.61-7.59$ ( $m, 4 \mathrm{H}, \mathrm{H}-5, \mathrm{H}-6, \mathrm{H}-12, \mathrm{H}-14), 0.42$ (s, 18H, H-21, H-22, H-23, H-24, H-25, H-26). 


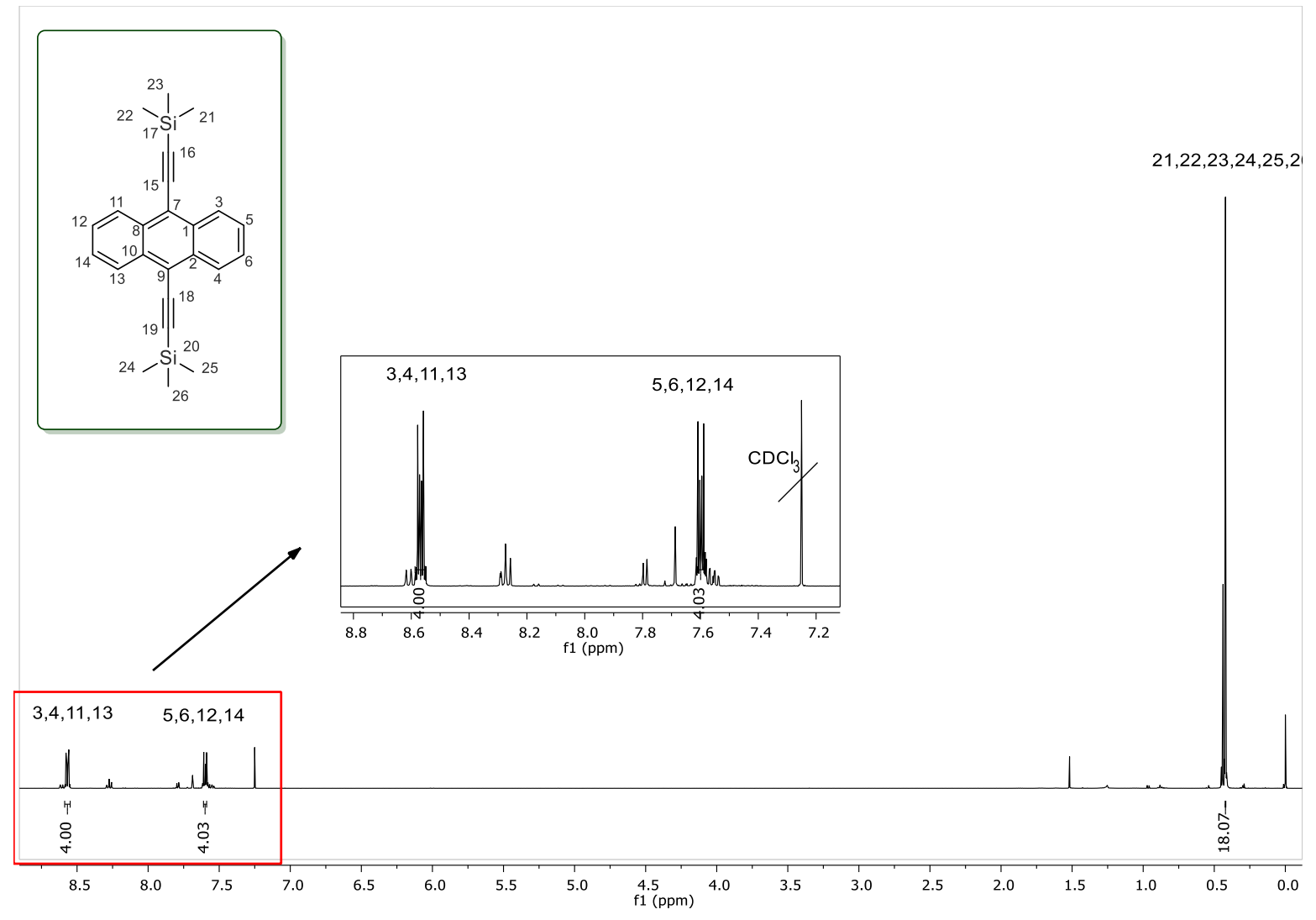

Figura 6-11. Espectro de 'H-RMN del Compuesto 10. 


\section{7. Ácido (E)-5,5'-(diazene-1,2-diil)di-isoftálico (Compuesto 14)}

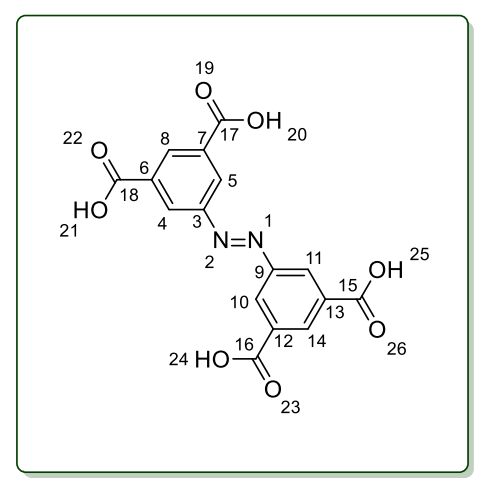

$2.1 \mathrm{~g}$ de ácido 5-nitroisoftálico, $1.3 \mathrm{~g}$ de $\mathrm{Zn}$ y $0.8 \mathrm{~g}$ de $\mathrm{NaOH}$ fueron agregados a 70 $\mathrm{ml}$ de una mezcla de EłOH/agua ( $\mathrm{v} / \mathrm{v} 7: 3$ ) en un matraz bola de $250 \mathrm{ml}$ equipado con agitador magnético. Esta mezcla fue calentada a reflujo durante $24 \mathrm{hrs}$. Se obtuvo un sólido entre gris y amarillo que fue recuperado por filtración y disuelto posteriormente en $50 \mathrm{ml}$ de una solución $1 \mathrm{M}$ de $\mathrm{NaOH}$, volvimos a filtrar para remover cualquier sólido insoluble. Finalmente, el filtrado fue acidificado con una solución $3 \mathrm{M}$ de $\mathrm{HCl}$ hasta llegar a un pH 3 para obtener un sólido amarillo.

- $\quad$ H NMR (500 MHz, DMSO- $d_{6}$ ): $\delta 13.06$ (s br, 4H, H-20, H-2, H-24, H-25), 7.65 (t, J $=1.5 \mathrm{~Hz}, 2 \mathrm{H}, \mathrm{H}-8, \mathrm{H}-14), 7.36(\mathrm{~d}, \mathrm{~J}=1.5 \mathrm{~Hz}, 4 \mathrm{H}, \mathrm{H}-4, \mathrm{H}-5, \mathrm{H}-10, \mathrm{H}-11)$.

- P.F.: $>250^{\circ} \mathrm{C}$ 


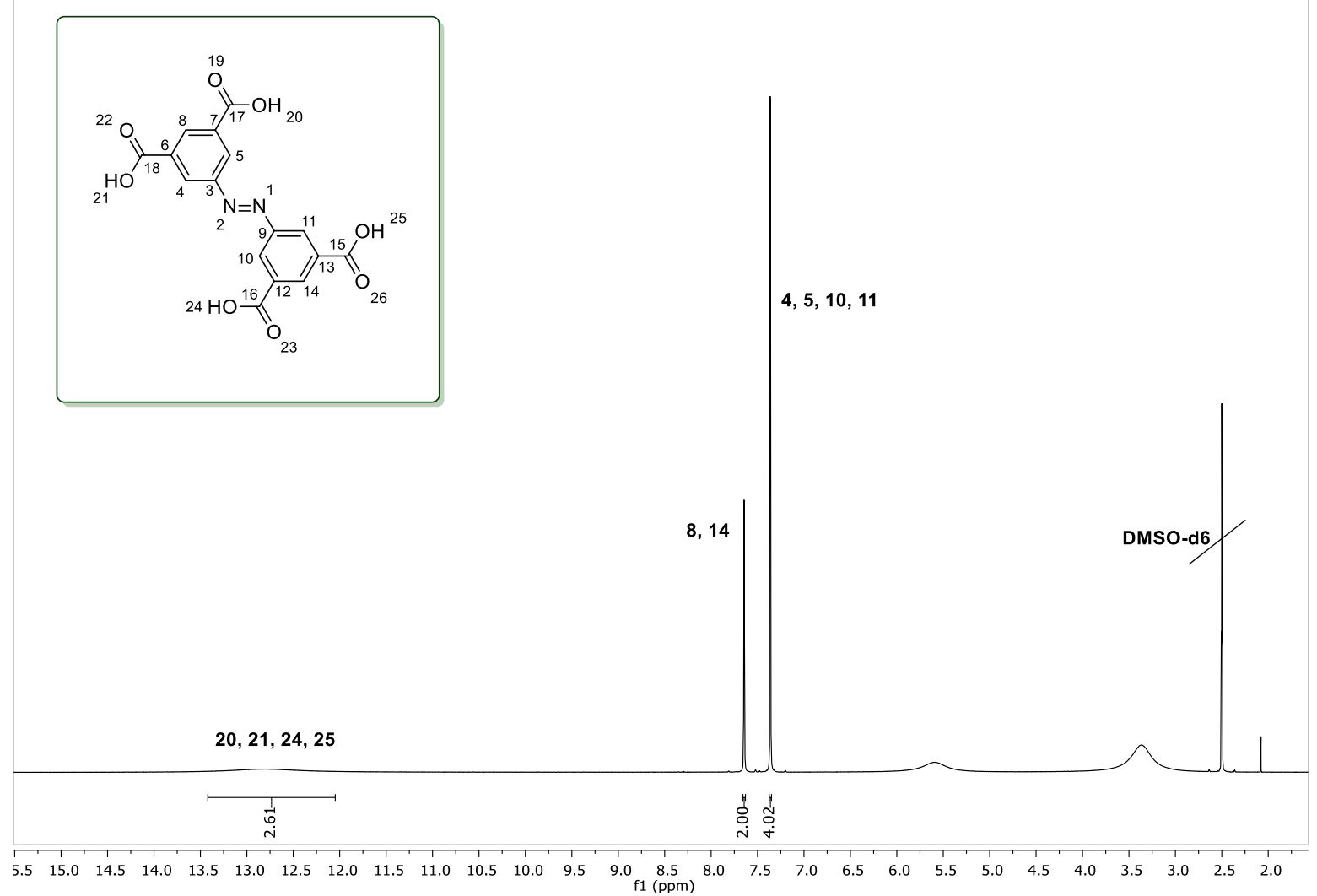

Figura 6-12. Espectro de ${ }^{1} \mathrm{H}-\mathrm{RMN}$ del Compuesto 13. 


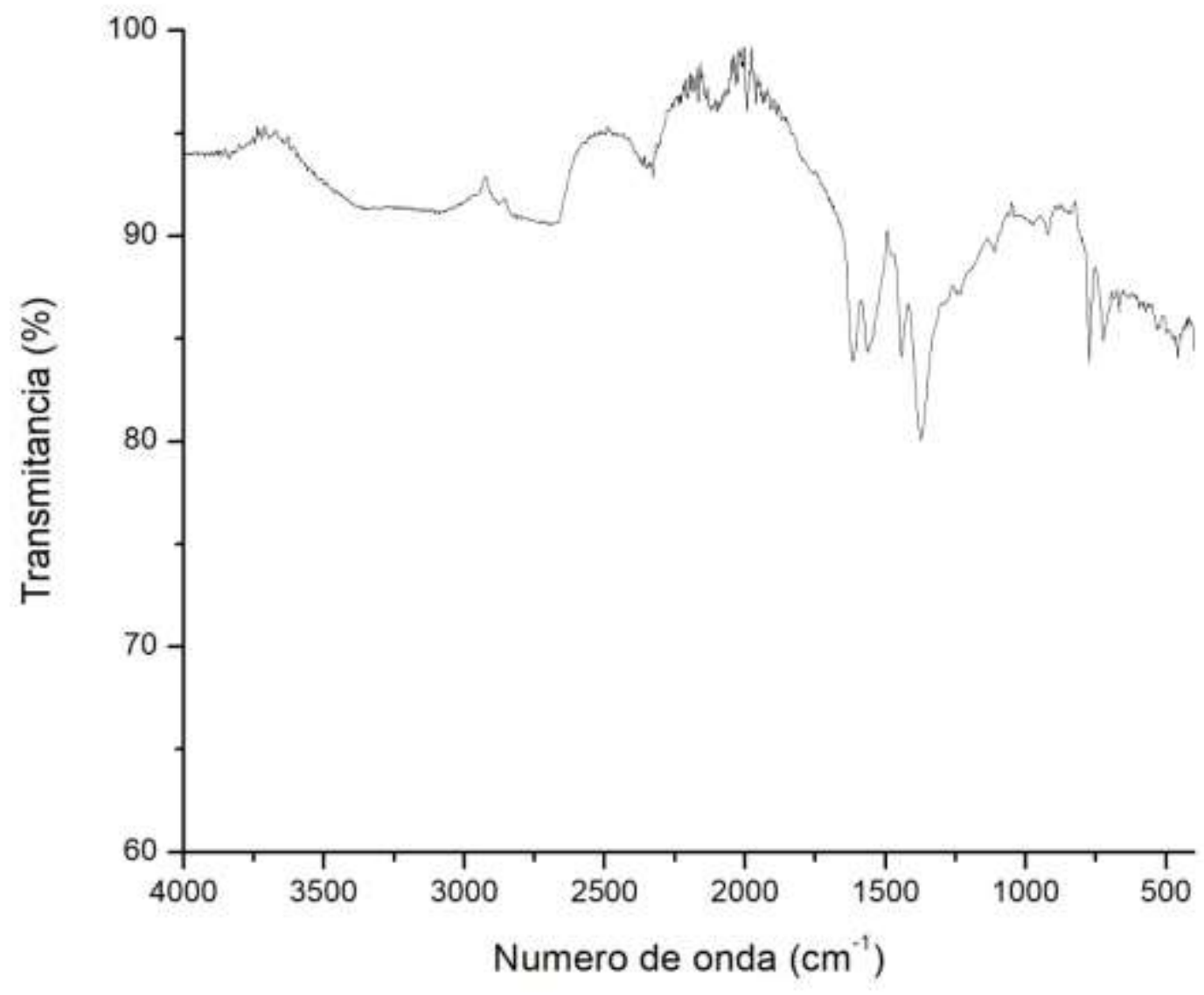

Figura 6-13. Espectro de FTIR-ATR del Compuesto 13. 


\section{8. Ácido (2E,2'E)-4,4'-1,4-fenilenobis(azadiil) bis(4- oxobut-2-enoico) (L5)}

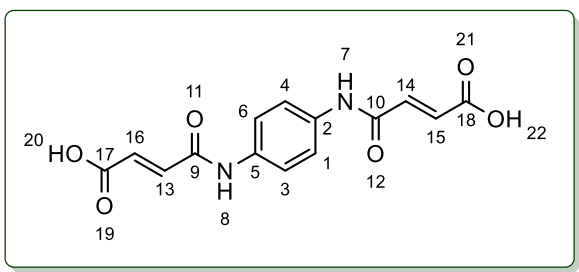

$2.0 \mathrm{~g}$ (7.46 mmol) de N, $\mathrm{N}^{\prime}-(1,4$-fenileno) dimaleimida fueron agregados a un matraz bola de $250 \mathrm{ml}$ equipado con un agitador magnético con $75 \mathrm{ml}$ de agua destilada para obtener una solución turbia (el reactivo no se disuelve). Posteriormente, una solución de $\mathrm{NaOH}(0.5 \mathrm{M}, \sim 27 \mathrm{ml})$ fue agregada lentamente, midiendo el pH de la solución constantemente y evitando sobrepasar un $\mathrm{pH}$ 12. Una vez que todo el reactivo de partida ha reaccionado se obtiene una solución amarilla traslúcida, la cual fue acidificada con una solución de $\mathrm{HCl}(3 \mathrm{M})$ hasta llegar a un $\mathrm{pH} 2$, Finalmente, el precipitado amarillo obtenido fue recuperado por filtración, lavado con agua destilada y secado a TA.

- 'H NMR (500 MHz, DMSO-d d $^{2}: \delta 13.24$ (s br, 2H, H-20, H-22), 10.45 (s, 2H, H-7, H8), 7.59 (s, 4H, H-l, H-3, H-4, H-6), 6.49 (dd, J = $80.5 \mathrm{~Hz}, 4 \mathrm{H}, \mathrm{H}-13, \mathrm{H}-14, \mathrm{H}-15, \mathrm{H}-$ 16).

- P.F.: $>250^{\circ} \mathrm{C}$ 


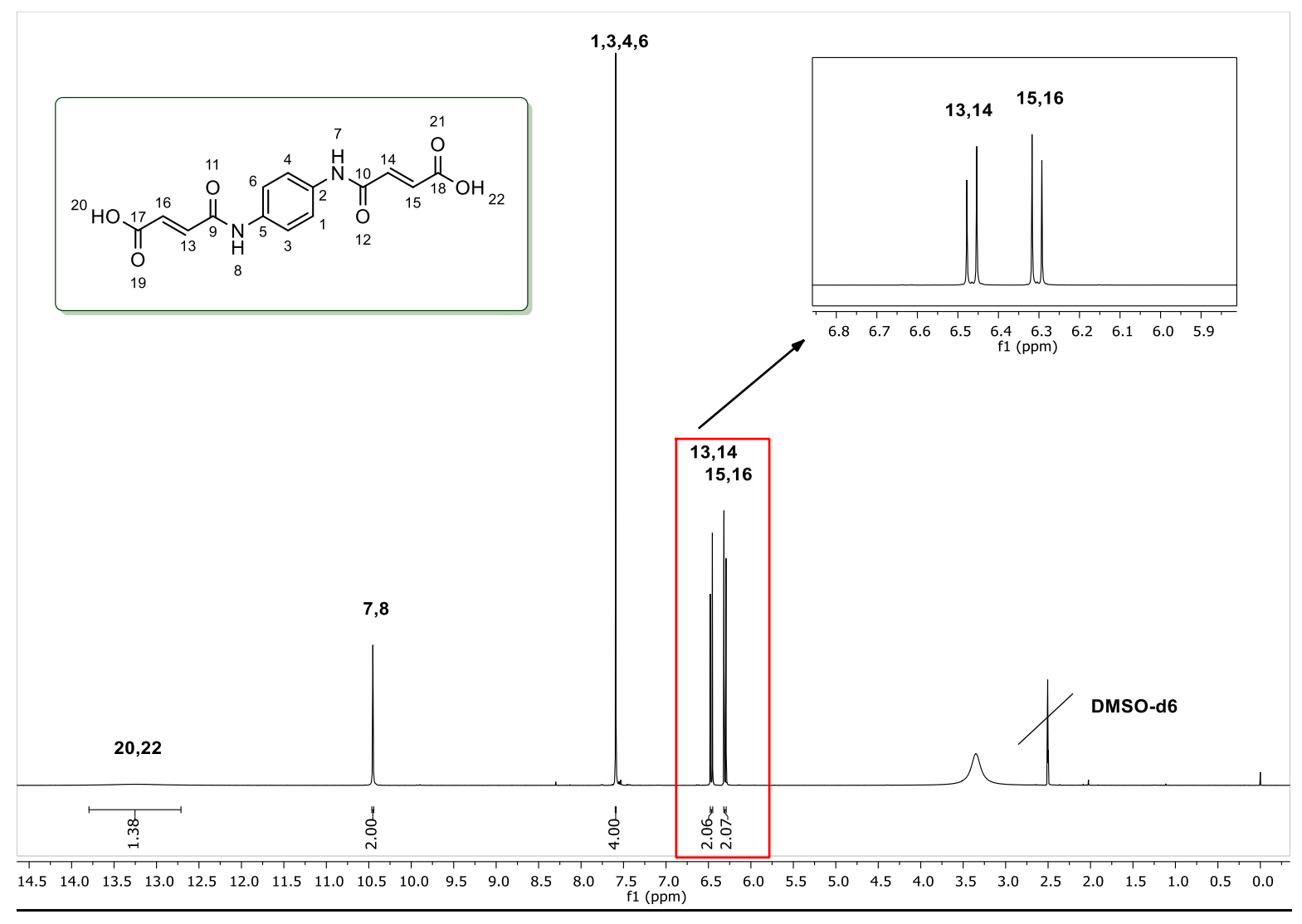

Figura 6-14. Espectro de ${ }^{1} \mathrm{H}-\mathrm{RMN}$ del Ligante L2. 


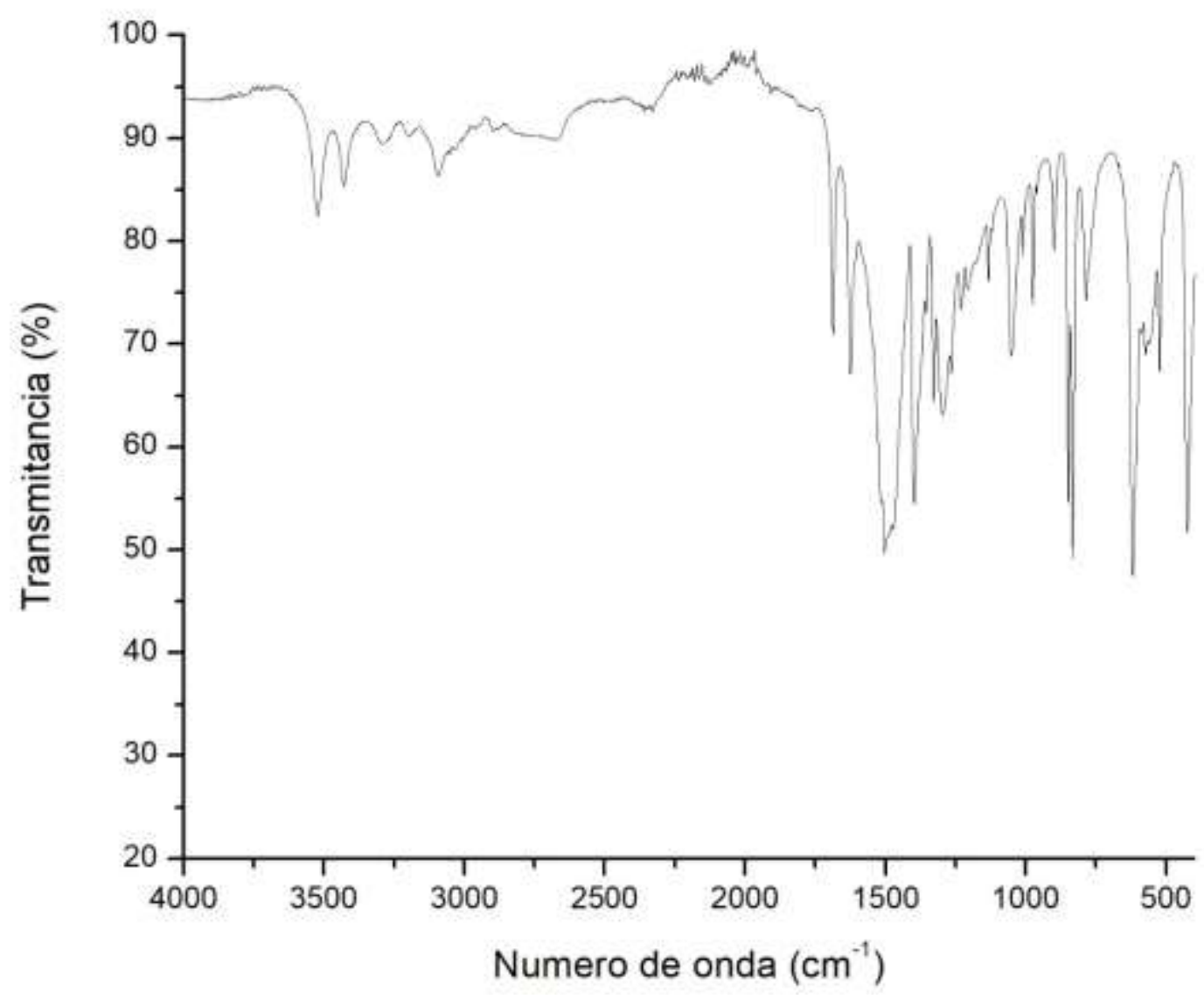

Figura 6-15. Espectro de FTIR-ATR del ligante L2. 


\section{REFERENCIAS}

[1] G. Férey, Chem. Mater., 2001, 13, 3084.

[2] G. Ferey, Chem. Soc. Rev., 2008, 37, 191.

[3] S. R. Batten, N. R. Champness, X.-M. Chen, J. Garcia-Martinez, S. Kitagawa, L. Öhrström, M. O'Keeffe, M. P. Suh, J. Reedijk, CrystEngComm, 2012, 14, 3001.

[4] C. Janiak, Dalt. Trans., 2003, 2781.

[5] O. M. Yaghi, M. O'Keeffe, N. W. Ockwig, H. K. Chae, M. Eddaoudi, J. Kim, Nature, 2003, 423, 705.

[6] S. R. Batten, N. R. Champness, X.-M. Chen, J. Garcia-Martinez, S. Kitagawa, L. Öhrström, M. O'Keeffe, M. Paik Suh, J. Reedijk, Pure Appl. Chem., 2013, 85, 1715.

[7] T. Loiseau, C. Serre, C. Huguenard, G. Fink, F. Taulelle, M. Henry, T. Bataille, G. Férey, Chem. - A Eur. J., 2004, 10, 1373.

[8] I. A. Ibarra, S. Yang, X. Lin, A. J. Blake, P. J. Rizkallah, H. Nowell, D. R. Allan, N. R. Champness, P. Hubberstey, M. Schröder, Chem. Commun., 2011, 47, 8304.

[9] S. S.-Y. Chui, S. M.-F. Lo, J. P. H. Charmant, A. G. Orpen, I. D. Williams, Science (80-. )., 1999, 283, 1148.

[10] S. R. Batten, S. M. Neville, D. R. Turner, Coordination Polymers. Design Analysis and Application. Cambridge: RSC Publishing, 2009.

[11] C. 11:5339 Y. Shibata, J. Coll. Sci., Imp. Univ. Tokyo, 1916, 1.

[12] M. Fujita, "From Hofmann Complexes to Organic Coordination Networks," in Metal-Organic Frameworks: design and application, L. R. MacGillivray, Ed. Wiley, 2010, 1.

[13] B. Hoskins, R. Robson, J. Am. Chem. Soc., 1989, 111, 5962.

[14] B. F. Hoskins, R. Robson, J. Am. Chem. Soc., 1990, 112, 1546.

[15] O. M. Yaghi, H. Li, J. Am. Chem. Soc., 1995, 117, 10401.

[16] S. Subramanian, M. J. Zaworotko, Angew. Chemie Int. Ed. English, 1995, 34, 2127.

[17] S. Kitagawa, S. Noro, "Coordination Polymers: Infinite Systems," in Comprehensive Coordination Chemistry II, Elsevier, 2003, 231. 
[18] A. Y. Robin, K. M. Fromm, Coord. Chem. Rev., 2006, 250, 2127.

[19] S. Kitagawa, R. Kitaura, S. Noro, Angew. Chem. Int. Ed. Engl., 2004, 43, 2334.

[20] M. Eddaoudi, D. B. Moler, H. Li, B. Chen, T. M. Reineke, M. O'Keeffe, O. M. Yaghi, Acc. Chem. Res., 2001, 34, 319.

[21] H. Furukawa, K. E. Cordova, M. O'Keeffe, O. M. Yaghi, Science (80-. )., 2013, $341,974$.

[22] W. Lu, Z. Wei, Z.-Y. Gu, T.-F. Liu, J. Park, J. Park, J. Tian, M. Zhang, Q. Zhang, T. Gentle III, et al., Chem. Soc. Rev., 2014, 43, 5561.

[23] T.-H. Chen, I. Popov, W. Kaveevivitchai, O.?. Miljani?, Chem. Mater., 2014, 26, 4322.

[24] S. M. Cohen, Chem. Rev., 2012, 112, 970.

[25] J. G. Nguyen, S. M. Cohen, J. Am. Chem. Soc., 2010, 132, 4560.

[26] N. B. Shustova, B. D. McCarthy, M. Dinc?, J. Am. Chem. Soc., 2011, 133, 20126.

[27] N. B. Shustova, T.-C. Ong, A. F. Cozzolino, V. K. Michaelis, R. G. Griffin, M. Dinca, J. Am. Chem. Soc., 2012, 134, 15061.

[28] S. Shimomura, S. Bureekaew, S. Kitagawa, "Porous Coordination Polymers Towards Gas Technology," in Molecular Networks, M. W. Hosseini, Ed. Springer, $2009,51$.

[29] C. Dey, T. Kundu, B. P. Biswal, A. Mallick, R. Banerjee, Acta Crystallogr. Sect. B Struct. Sci. Cryst. Eng. Mater., 2014, 70, 3.

[30] N. Stock, S. Biswas, Chem. Rev., 2012, 112, 933.

[31] S. Qiu, G. Zhu, Coord. Chem. Rev., 2009, 253, 2891.

[32] Y. R. Lee, J. Kim, W.-S. Ahn, Korean J. Chem. Eng., 2013, 30, 1667.

[33] C. Janiak, J. K. Vieth, New J. Chem., 2010, 34, 2366.

[34] J. Lee, O. K. Farha, J. Roberts, K. A. Scheidt, S. T. Nguyen, J. T. Hupp, Chem. Soc. Rev., 2009, 38, 1450.

[35] J. Gascon, A. Corma, F. Kapteijn, F. X. Llabrés i Xamena, ACS Catal., 2014, 4, 361.

[36] R. J. Kuppler, D. J. Timmons, Q.-R. Fang, J.-R. Li, T. A. Makal, M. D. Young, D. Yuan, D. Zhao, W. Zhuang, H.-C. Zhou, Coord. Chem. Rev., 2009, 253, 3042.

[37] P. Horcajada, R. Gref, T. Baati, P. K. Allan, G. Maurin, P. Couvreur, G. Férey, R. E. Morris, C. Serre, Chem. Rev., 2012, 112, 1232.

[38] P. Horcajada, C. Serre, M. Vallet-Regí, M. Sebban, F. Taulelle, G. Férey, Angew. 
Chemie - Int. Ed., 2006, 45, 5974.

[39] E. G. Berthier, M. J. S. Dewar, H. Fischer, K. Fukui, H. Hartmann, H. H. Jaffe, J. Jortner, W. Kutzelnigg, K. Ruedenberg, E. Scrocco, et al., Applied CrossCoupling Reactions, 80. Berlin, Heidelberg: Springer Berlin Heidelberg, 2013.

[40] N. Miyaura, Ed., Cross-Coupling Reactions, 219. Berlin, Heidelberg: Springer Berlin Heidelberg, 2002.

[41] J. Tsuji, H. Takahashi, J. Am. Chem. Soc., 1965, 87, 3275.

[42] D. Blakemore, "Suzuki-Miyaura Coupling," in Synthetic Methods in Drug Discovery, 1, D. C. Blakemore, P. M. Doyle, and Y. M. Fobian, Eds. Royal Society of Chemistry, 2016.

[43] X. Lin, I. Telepeni, A. J. Blake, A. Dailly, C. M. Brown, J. M. Simmons, M. Zoppi, G. S. Walker, K. M. Thomas, T. J. Mays, et al., J. Am. Chem. Soc., 2009, 131, 2159.

[44] J. Zhu, K. Zhong, Y. Liang, Z. Wang, T. Chen, L. Y. Jin, Tetrahedron, 2014, 70, 1230.

[45] S. Wang, X. Wang, L. Li, R. C. Advincula, J. Org. Chem., 2004, 69, 9073. 
Sintesis de ligantes

carboxilados como

precursores de Polímeros de

Coordinacion porosos (PCPs).

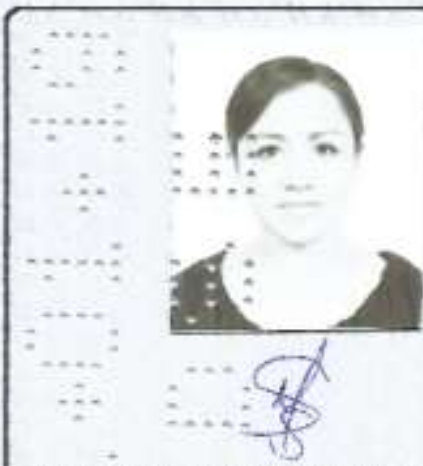

MVIATAA ALEJANDRA SANCHEZ SERRATOS

$\because \cdots: \quad$ ALUMNA

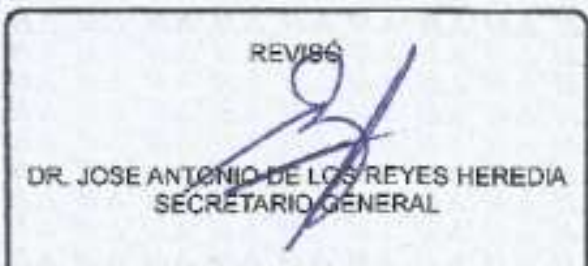

En la Ciudad de Mexico, se presentaron a 1as 11:00 horas del dia 21 del mes de dioiembre del año 2016 en la unidad Irtapalapa de la Universidad Autónoma Metropolitana, los suscritos miembros del jurado:

DR. HIRAM ISAAC BELTRAN CONDE

DR. ILICH ARGEL IBARRA ALVARADO

DR. ALEJANDRO ISLAS JACOME
Bajo 1a Presidencia del primero y con carácter de Secretario el ditimo, se Ieunieron para proceder al Examen de Grado cuya denominación aparece al margen, para la obtención del gracio de:

MABSTRA BN CIENCIAS (OUIMICA)

DE: MAYRA ALEJANORA SANCBEZ SERRATOS

* de acuerdo con el artieulo 78 fracción III del Reglamento de Eatudion Superfores de la Universidad Autónoma Metropoittana, los miembros del jurado resolvieron:

$$
\text { Apinobi }
$$

Acto continuo, el presidente del jurado comunico a la interesada el resultado de la evaluación $y$, en caso aprobatorio, le fue tomada la protesta.
DIRECTOR DE LA DMISION DE CBI

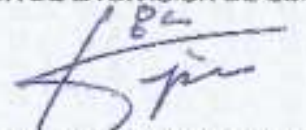

DR. JESUS ALBERTO OCHOA TAPIA

VOCAL

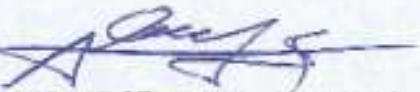

OR. ILICH ARGEL IBARRA ALVARADO

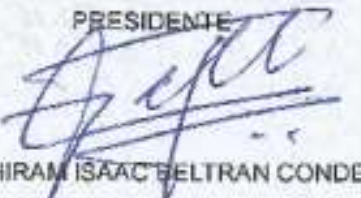

DR. HIRAY/ISAAC QELTRAN CONDE

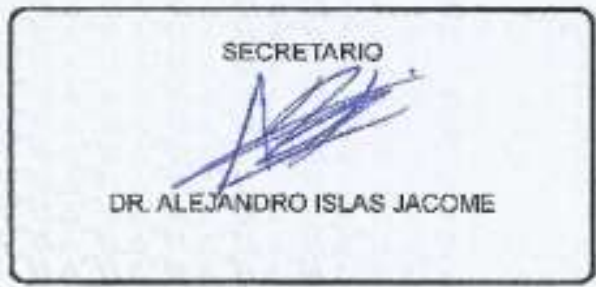

